\title{
EXPERIMENTAL STUDY OF RESILIENT PREFABRICATED STEEL FRAME WITH ALL-BOLTED BEAM-TO-COLUMN CONNECTIONS
}

\author{
Ai-Lin Zhang ${ }^{1,2,3}$, Guang-Hao Shangguan ${ }^{3}$, Yan-Xia Zhang ${ }^{1,3,{ }^{*}}$, Qing-Bo Wang ${ }^{3}$ and Wen-Chao Cai ${ }^{3}$ \\ Beijing Advanced Innovation Center for Future Urban Design, Beijing University of Civil Engineering and Architecture, Beijing, China \\ ${ }^{2}$ Beijing Engineering Research Center of High-rise and Large-span Prestressed Steel Structure, Beijing University of Technology, Beijing, China \\ ${ }^{3}$ School of Civil and Transportation Engineering, Beijing University of Civil Engineering and Architecture, Beijing, China \\ *(Corresponding author: E-mail: zhangyanxia@bucea.edu.cn)
}

\section{A B S T R A C T}

To avoid welding on a construction site, this paper proposes a novel resilient prefabricated steel frame with all-bolted beamto-column connections (ABRPSF), which is optimized based on a resilient prefabricated steel frame with mixed welded and bolted beam-to-column connections (WBRPSF) that was proposed and investigated in a previous study. Four-story, 3 $\times 5$ bay prototype structures of the ABRPSF and WBRPSF are designed, and their substructures are used to conduct pseudodynamic tests, whose results are then compared to investigate the seismic behavior of ABRPSFs. The results indicate that the seismic behavior and recentering capacity of a new structural system composed of ABRPSFs are similar to those of WBRPSFs; in addition, the ABRPSF improves the assembly efficiency significantly and can be adopted as a reliable alternative to the WBRPSF.
ART I CLE H I S T O RY

$\begin{array}{ll}\text { Received: } & \text { 18 September } 2019 \\ \text { Revised: } & \text { 12 June 2020 } \\ \text { Accepted: } & \text { 22 June 2020 }\end{array}$

\section{KE Y W O R D S}

Resilient prefabricated steel frame All-bolted beam-to-column connection;

Mixed welded and bolted beam-tocolumn connection; Pseudo-dynamic test; Seismic behavior

\section{Introduction}

Compared with conventional moment-resisting steel frames, self-centering steel moment-resisting frames (SC-MRFs) exhibit better performances in controlling structural damage, absorbing seismic energy through plastic deformation of energy dissipation devices, and rehabilitating the initial function of a steel frame following intensive seismic actions. In the past decades, this new structural system has been integrated significantly by researchers at worldwide. Early experimental studies pertaining to SC-MRFs were initiated by Ricles et al. [1, 2]. Subsequently, these studies were extended to novel configurations and improvements in energy dissipation devices, for which representative studies based on energy dissipating bars were performed by Christopoulos et al. [3], those based on bolted web friction devices were performed by Tsai et al. [4], and those based on bottom flange friction damped devices were performed by P. Rojas et al. [5] and Wolski et al. [6]. Additionally, Khoo et al. [7] proposed a self-centering sliding hinge joint to achieve the intended function by mainly relying on friction ring springs. Garlock et al. [8] conducted inelastic cyclic loading tests of six full-scale post-tensioned (PT) steel connection with bolted top and seat angles and proposed closed-form expressions. Lin et al. [9] proposed a steel SC-MRF, conducted quasistatic pushover tests under maximum considered earthquake ground motions, and investigated the performance of the SC-MRF under an earthquake design basis [10]. Georgios et al. [11] proposed a computational framework for the automated seismic design of SC-MRFs based on experimental results. Vasdravellis et al. [12] proposed a new self-centering steel PT connection using high-strength steel PT bars to induce self-centering behavior and cylindrical pins with an hourglass shape to provide an enhanced deformation capacity. Steel structures constructed using shape memory alloys for achieving self-centering capabilities have been widely investigated [13-17]. Meanwhile, innovative structural configurations of self-centering steel braces in steel frames have been designed and corresponding tests have been conducted [18-22]. Based on the abovementioned studies, Zhang et al. proposed novel self-centering prefabricated steel frames [23-24], resilient prefabricated steel frames [25], and prefabricated beam-column connections with short strands in a self-centering steel frame [26]; these structures not only demonstrate advantageous seismic and recentering performances, but also avoid the potential issue of aerial pretension in the aforementioned beam-through self-centering steel frames.

Herein, we propose an original all-bolted beam-to-column connection resilient prefabricated steel frame (ABRPSF) based on previous studies [23-26]. This new steel frame has an improved beam-to-column connection, which is better than welded beam-to-column connection resilient prefabricated steel frames (WBRPSFs) [24]. In ABRPSFs, all-bolted connections are achieved using L-plates and high-strength bolts to avoiding potential issues from on-site welding. Structural configurations of ABRPSFs and WBRPSFs have been investigated, and pseudo-dynamic tests have been performed on both steel frames to compare and investigate their seismic performances and recentering capacities. Results indicated that the deformation performance, gap-opening mechanism, PT force variation, and strain development conditions of the ABRPSF are similar to those of the WBRPSF, whereas its energy dissipation capacity is more favorable. The ABRPSF not only possesses the advantages of the WBRPSF, but also improves the assembly efficiency by avoiding welding.

\section{Details of WBRPSF and ABRPSF}

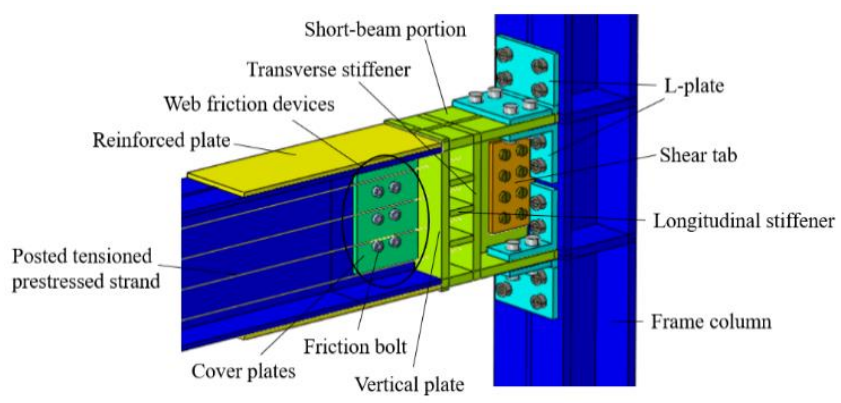

Fig. 1 Construction details of ABRPSF

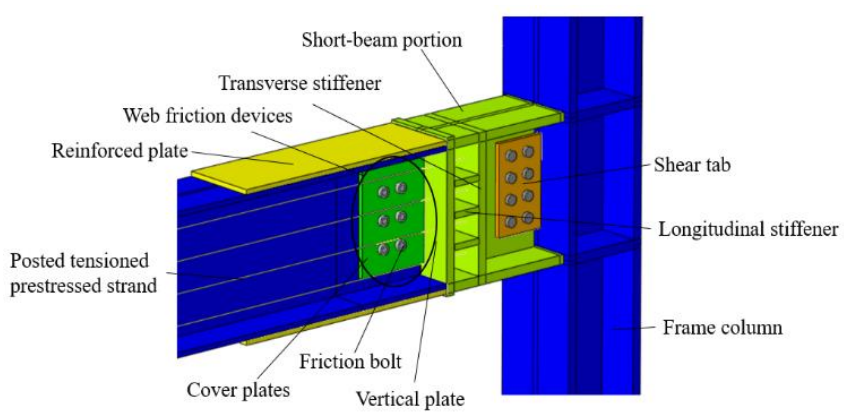

Fig. 2 Construction details of WBRPSF

Fig. 1 shows the structural details of the ABRPSF. The frame column and the assembled prestressed beam were connected by L-plates and high-strength bolts, which were used to connect the beam and column flange as well as the bolt beam web and shear tab that were welded to the column flange. As shown 
in Fig. 1, the entire beam assembly was primarily composed of steel strands as well as short and long beam portions. The steel strands were arranged parallel to the beam length direction and prestressed to connect two short beam portions and a long beam portion. Each short beam portion included an I-section beam, a vertical plate, transverse stiffeners, and longitudinal stiffeners. The vertical plate was reliably welded to the internal end of the I-section beam to provide a close and stable contact with the long beam portion. Transverse stiffeners were welded to the I-section beam web as the anchor end of the steel strands; additionally, small-sized longitudinal stiffeners were welded to the surfaces of the transverse stiffeners, I-section beam web, and vertical plate to strengthen the anchored regions of the transverse stiffeners. The long beam portion mainly comprised an I-section beam, reinforced plates, and web friction devices. The reinforced plate was welded to the outside surface of the beam end flange to avoid local buckling. The web friction devices comprised elongated holes that were opened on the beam web to allow the slippage of high-strength bolts, cover plates welded on the vertical plate in advance, and a brass plate sandwiched between the cover plate and I-section beam web to ensure a stable friction behavior.

Fig. 2 shows the structural details of the WBRPSF, which are identical to

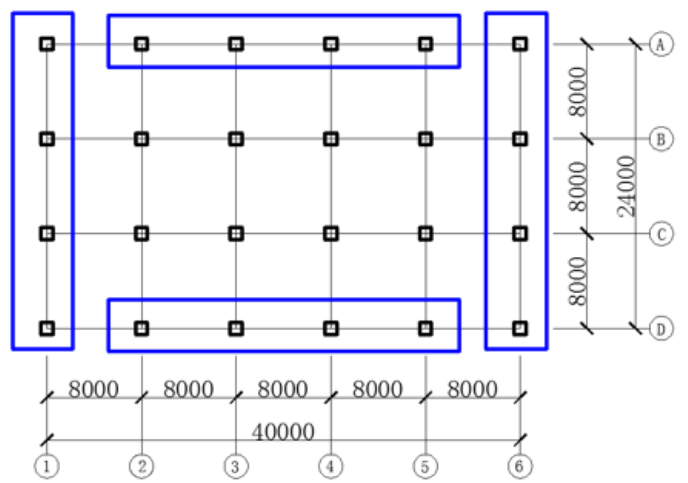

Fig. 3 Layout of prototype structure of both steel frames

\subsection{Substructure}

To simplify the pseudo-dynamic test and minimize negative effects on the test results, a single span of steel frame was selected as a substructure, as shown in Fig. 4, in which the first story was designed as a testing substructure, whereas other stories constituted the computing substructure. Considering the limited conditions of the laboratory, a 0.75 scale of the prototype structure was adopted to conduct the test, in which the frame column sections was determined by adopting the same axial compression ratio with the corresponding columns in the prototype structure. The section dimensions of the columns, short beam portions, and long beam portions were $\mathrm{H} 300 \times 300 \times 20 \times 30, \mathrm{H} 482 \times 250 \times 18$ $\times 30$, and $\mathrm{H} 450 \times 250 \times 14 \times 16$, respectively. The column web stiffeners at the beam-to-column panel zone, located at the level altitude with beam flanges, was designed to be $30 \mathrm{~mm}$ thick to avoid local buckling at the contact area of the column flange. The transverse and longitudinal stiffeners installed at the short beam portions were $30 \mathrm{~mm}$ and $20 \mathrm{~mm}$ thick, respectively. The vertical plate between the short and long beam portions was $30 \mathrm{~mm}$ thick. Additionally, six M24 (with a nominal diameter of $24 \mathrm{~mm}$ ) 10.9s high-strength bolts were adopted in the web friction devices and eight M20, 10.9s [27] high-strength those of the ABRPSF except the beam-to-column connection. Unlike the ABRPSF, the frame column and the assembled prestressed beam were connected by welding the beam to the column flanges as well as the bolt beam webs to the shear tabs that were welded to the column flange. The entire beam assembly, similar to the prestressed steel beam, was proposed by our research group [24].

\section{Prototype structure and substructure}

\subsection{Prototype structure}

Four-story, $3 \times 5$ prototype structures of the WBRPSF and ABRPSF were designed, and the plane layout is shown in Fig. 3; meanwhile, the substructure schematics of both steel frames are shown in Fig. 4. The first story was $3.9 \mathrm{~m}$ high, whereas the second to fourth story was $3.6 \mathrm{~m}$ high. Each story was $8 \mathrm{~m}$ long, and the steel frames highlighted by blue brackets were designed as a WBRPSF or an ABRPSF. The section dimensions of the frame column and frame beam were $\mathrm{H} 400 \times 400 \times 34 \times 34$ and $\mathrm{H} 588 \times 300 \times 12 \times 20$, respectively.

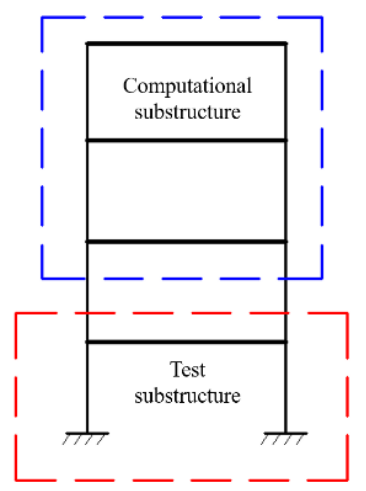

Fig. 4 Substructure schematics of both steel frame

bolts were used in the beam-to-column connection. Each steel strand was composed of 19 steel wires that functioned comprehensively with a nominal diameter of $21.8 \mathrm{~mm}$, nominal section area of $312.9 \mathrm{~mm}^{2}$, and nominal ultimate tensile strength of $T_{u}=1860 \mathrm{~N} / \mathrm{mm}^{2}$; furthermore, the wires were prestressed to $0.25 \mathrm{~T}_{\mathrm{u}}$ (we set the initial PT force as $\mathrm{T}_{0}$ ). For the ABRPSF in particular, two large L-shaped plates $(\mathrm{L} 200 \times 250 \times 24)$, four small L-shaped plates (L200 $\times$ $95 \times 24$ ), and 24 M24 high-strength bolts were additionally adopted to ensure a reliable connection between the beam flange and column flange.

\subsection{Material properties}

Q345B steel was adopted for both the WBRPSF and ABRPSF, and the material properties obtained from the completed material tests are listed in Table 1. The steel strands used in the test specimens remained in the elastic state during the entire loading process. Three group material tests of steel strands were conducted, and their properties are listed in Table 2. The experimental results show that the friction coefficient between the brass plate $(3 \mathrm{~mm})$ and steel plate was 0.34 .

\section{Table 1}

Tensile testing results of standard samples

\begin{tabular}{cccccc}
\hline Thickness $(\mathrm{mm})$ & Yield strength $(\mathrm{MPa})$ & Ultimate strength(MPa) & Percent elongation at fracture $(\%)$ & Elastic modulus $\times 10^{5}(\mathrm{MPa})$ & Ratio of tensile and yield strength \\
\hline 14 & 384 & 561 & 27.0 & 2.15 & 1.46 \\
16 & 392 & 555 & 23.3 & 2.06 & 1.42 \\
18 & 381 & 555 & 25.3 & 2.22 & 1.46 \\
20 & 384 & 550 & 25.7 & 2.09 & 1.43 \\
22 & 388 & 574 & 26.8 & 2.09 & 1.48 \\
30 & 350 & 505 & 26.5 & 2.07 & 1.44 \\
\hline
\end{tabular}


Table 2

Prestressed strand material properties

\begin{tabular}{|c|c|c|c|c|}
\hline Strand & Specimen & Yield strength (MPa) & Ultimate strength $(\mathrm{MPa})$ & Elastic modulus (GPa) \\
\hline & 1 & 1728.3 & 1894.5 & 203 \\
\hline $1 \times 19$ & 2 & 1727.1 & 1895.8 & 205 \\
\hline \multirow[t]{2}{*}{$1860 \mathrm{MPa}$} & 3 & 1732.8 & 1875.4 & 200 \\
\hline & average value & 1729 & 1889 & 203 \\
\hline
\end{tabular}

\section{Pseudo-dynamic test}

\subsection{Testing setup and loading devices}

The testing setup schematics of the pseudo-dynamic test are shown in Fig. 5; the multistory structural remote cooperative pseudo-dynamic test platform [24] was used to complete the loading process. Seismic actions were performed on the steel frame using a 200t lateral actuator attached to the reaction wall. Two end vertical actuators were fixed on the reaction frame, and they were placed on the top of both columns to simulate the axial forces transferred from the upperfloor columns; a middle vertical actuator and a force transfer girder were adopted to simulate the live load transferred from the upper floor. Both column feet were fixed on the column bases, whose six degrees-of freedom were restrained by adopting both pressure beams. Moreover, two lateral supports were installed to avoid the possible out-plane instability of the steel frame. Earthquake ground motion records were input to the platform structure software to calculate the corresponding displacement, which was then used to control the lateral actuator. To achieve this, the platform structure must be input to the floor quality and theoretical interstory restoring force model, similar to that investigated in a previous study [24]. The photographs of the ABRPSF and WBRPSF are shown in Figs. 6 and 7, respectively.

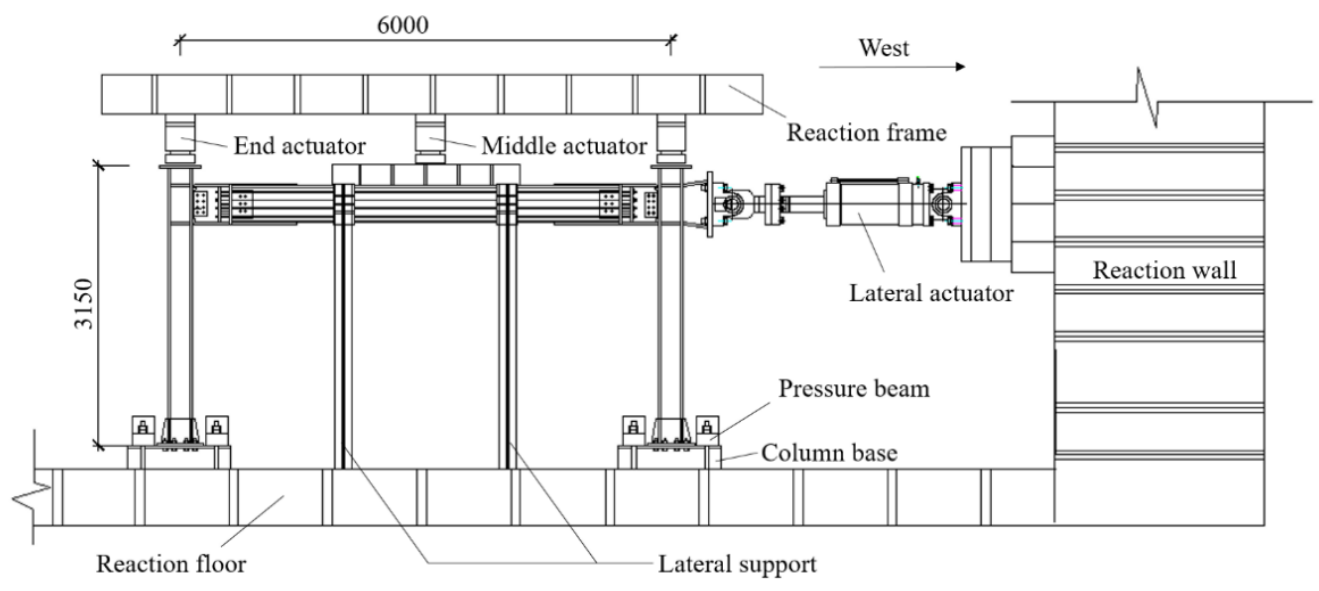

Fig. 5 Test setup schematic

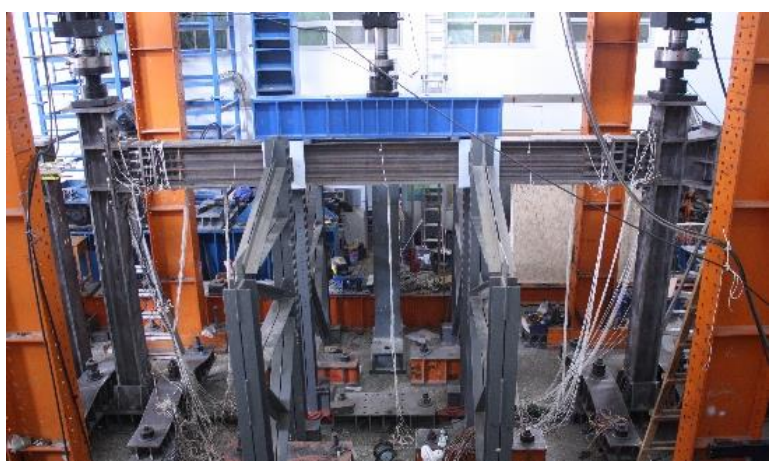

Fig. 6 Photograph of ABRPSF

\subsection{Selection of earthquake ground motions}

Ground motions from the EL-Centro and Wenchuan earthquakes were selected to conduct the pseudo-dynamic test; the time history curves of the earthquake accelerations for the ground motion records are shown in Figs. 8 and 9, where the peak ground accelerations (PGAs) are modified to $0.4 \mathrm{~g}$. The acceleration response spectrums of the EL-Centro, Wenchuan, and standard ground motion records are shown in Fig. 10. The result of the structural computation shows that the first period of the prototype structure was $1.23 \mathrm{~s}$, and a damping ratio of 0.05 was used according to GB50011-2016 [28].

Both earthquake ground motions were input into the testing equipment

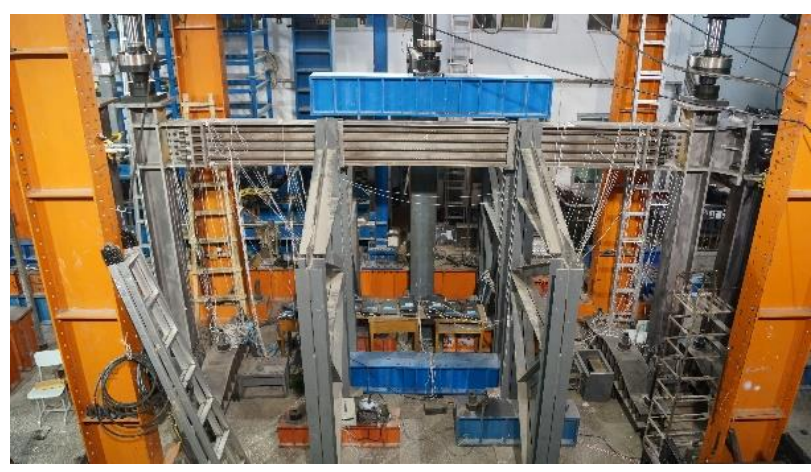

Fig. 7 Photograph of WBRPSF

under various peak ground accelerations, i.e., 0.07, 0.20, 0.40, and 0.51g, which corresponded to four seismic levels, i.e., 8-degree frequent earthquake, 8-degree fortification earthquake, 8-degree rare earthquake, and 8.5-degree rare earthquake, as described in GB50011-2016 [28]. The ground motion records of Wenchuan with PGAs of $0.62,0.81,1.0$, and $1.2 \mathrm{~g}$ were input into the testing equipment to study the seismic performance of both steel frames under higher seismic levels. 


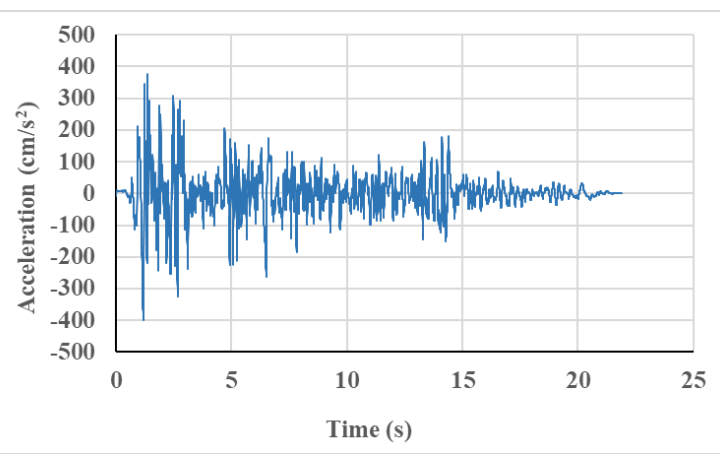

Fig. 8 EL-Centro ground motion record

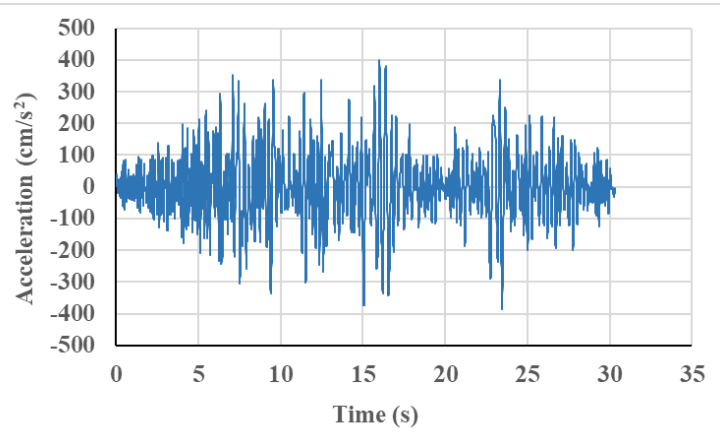

Fig. 9 Wenchuan ground motion record

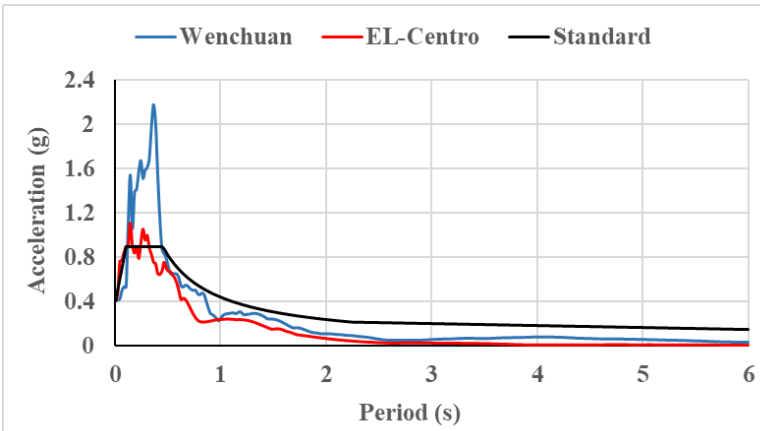

Fig. 10 Acceleration response spectrum comparison

\subsection{Measurement devices}

Fig. 11 shows the arrangement of various measurement instruments for the ABRPSF. Strain gauges were fixed to measure the strain level of typical positions, such as the column foot web and flange, column panel zone, beam reinforced plate, beam flange close to column, L-plate, vertical plate, and beam web. Furthermore, three-directional strain gauges were adopted on the area with complex stress distribution conditions. The PT forces of eight steel strands were monitored using pressure sensors with a range of $250 \mathrm{kN}$. Additionally, eight small displacement meters were installed to measure the gap opening size. The actuator force was monitored using a built-in sensor.

Fig. 12 shows the arrangements of various measurement instruments for the WBRPSF, which are identical to those for the ABRPSF except for the strain gauges on the L-plates.
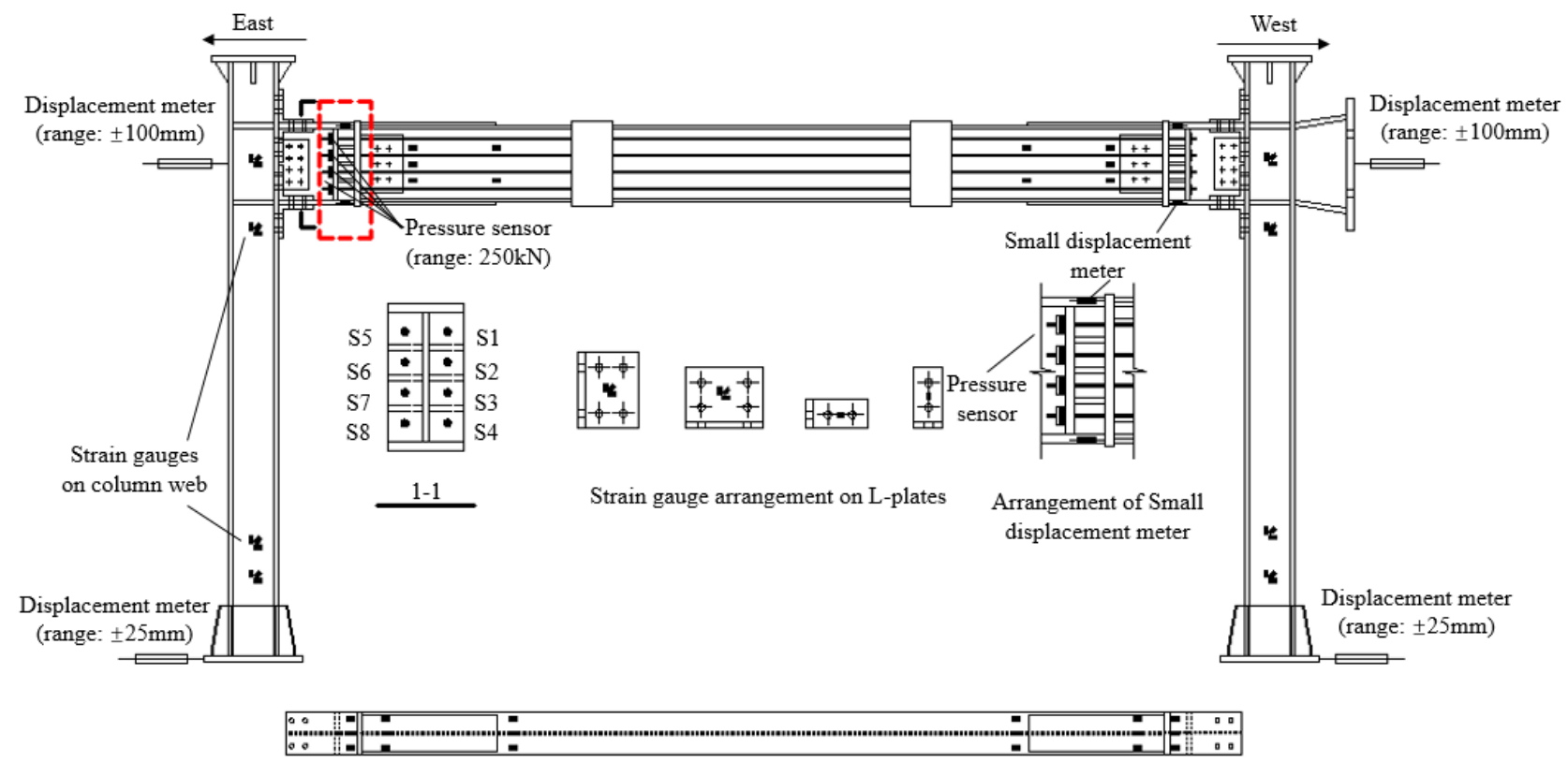

Strain gauge arrangement on upper flange of the assembled beam

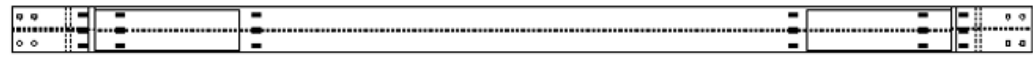

Strain gauge arrangement on lower flange of the assembled beam

Fig. 11 Arrangement of measurement devices for ABRPSF 

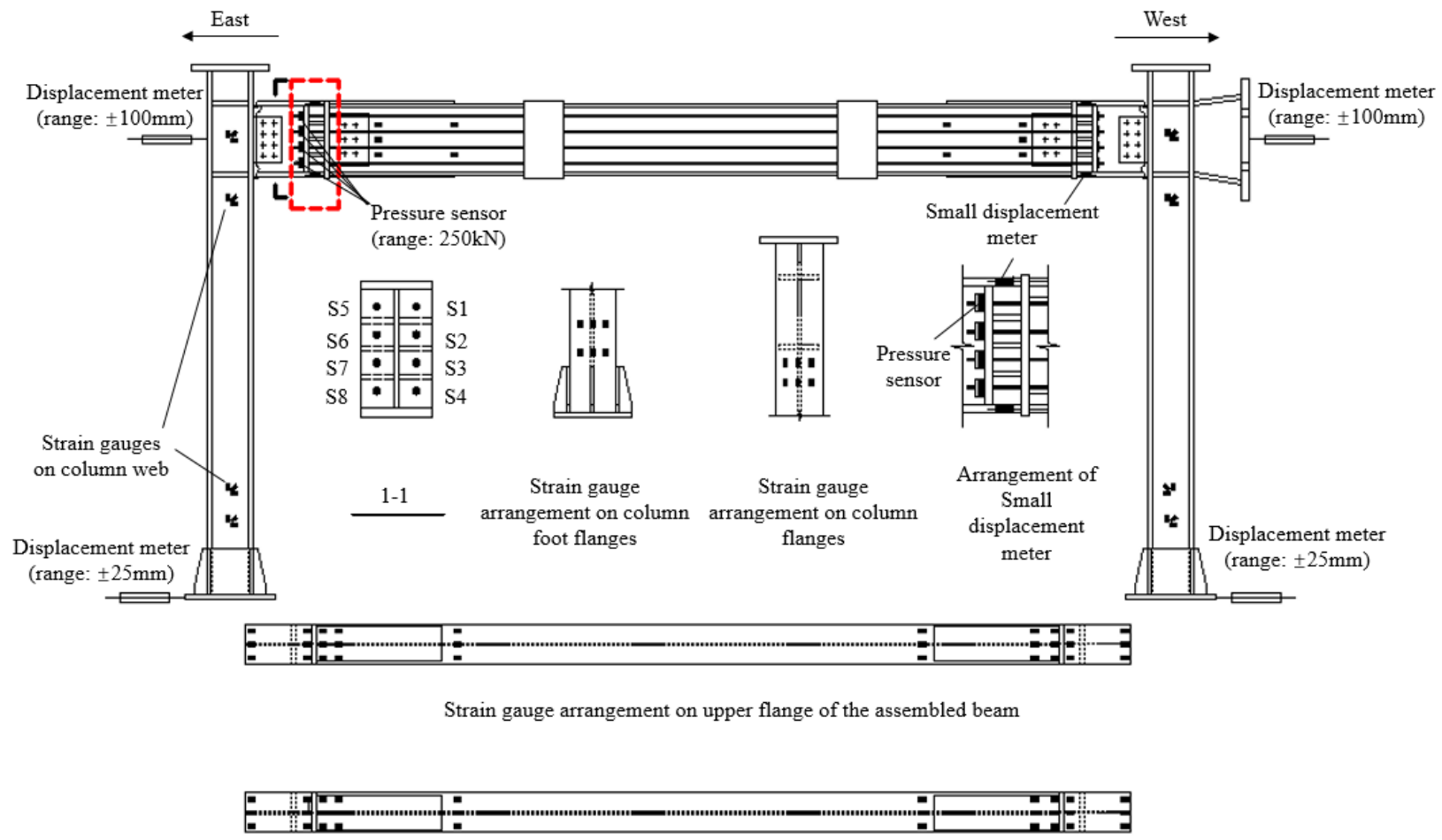

Strain gauge arrangement on lower flange of the assembled beam

Fig. 12 Arrangement of measurement devices for WBRPSF

\section{Comparison of Testing Results of ABRPSF and WBRPSF}

During testing, both EL-Centro and Wenchuan seismic records were adopted to excite the both steel frames. When the seismic level was under a PGA of $0.62 \mathrm{~g}$, the ABRPSF and WBRPSF were in the elastic state; therefore, when the PGA exceeded $0.62 \mathrm{~g}$, a certain degree of plasticity developed in the steel frames. The design goal that we set was "no gap opening and no damage occurs during frequent earthquakes, gap openings are formed to dissipate energy, and no damage occurs to the main structure under fortification earthquake action, i.e., only extremely small structural damages occur and the structure can still operate normally during rare or extremely rare earthquakes." Subsequently, only the Wenchuan seismic record was used to conduct the excitation process.

\subsection{Deformation}

The displacement responses of the ABRPSF and WBRPSF under various seismic levels of the EL-Centro seismic record are shown in Figs. 13(a)-(d), which reveal similar variation trends for both structural systems. Table 3 shows the maximum displacement responses and the corresponding story drifts for the ABRPSF and WBRPSF under the EL-Centro seismic records. When PGA =
$0.07 \mathrm{~g}$, the maximum displacements for the ABRPSF and WBRPSF were still relatively low, i.e., 4.95 and $3.74 \mathrm{~mm}$, respectively, and the corresponding story drifts were 1/594 and 1/786 rad, respectively, under a PGA of $0.20 \mathrm{~g}$. Meanwhile, the maximum displacements for the ABRPSF and WBRPSF were was 13.34, and $9.37 \mathrm{~mm}$, respectively, whereas their story drifts were $1 / 220$ and $1 / 334 \mathrm{rad}$, respectively. Under rare earthquake motions, the displacement responses for both steel frames were relatively larger. When PGA $=0.40 \mathrm{~g}$, the displacements of the ABRPSF and WBRPSF were 20.4 and $18.06 \mathrm{~mm}$, respectively, whereas their story drifts were 1/144 and 1/163 rad, respectively. Meanwhile, when PGA $=0.51 \mathrm{~g}$, the displacements of the ABRPSF and WBRPSF were 26.6 and 23.36 $\mathrm{mm}$, respectively, whereas their story drifts were $1 / 110$ and $1 / 126 \mathrm{rad}$, respectively. We observed that the displacement response of the ABRPSF increased slightly compared with that of the WBRPSF, indicating that the lateral rigidity of the ABRPSF was smaller than that of the WBRPSF. When PGA = $0.51 \mathrm{~g}$, the maximum story drift was $1 / 110$ and $1 / 126 \mathrm{rad}$ for the ABRPSF and WBRPSF, respectively, whereas the maximum story drifts of both steel frames did not exceed the elastic story drift limit of a frame defined in the Code for Seismic Design of Buildings (1/50); this implies that the structure was safe, and that both frames can return to their initial positions after an earthquake.

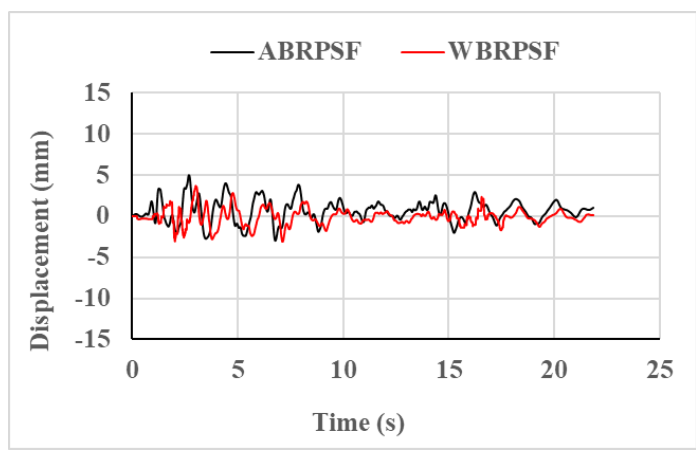

(a) $\mathrm{PGA}=0.07 \mathrm{~g}$

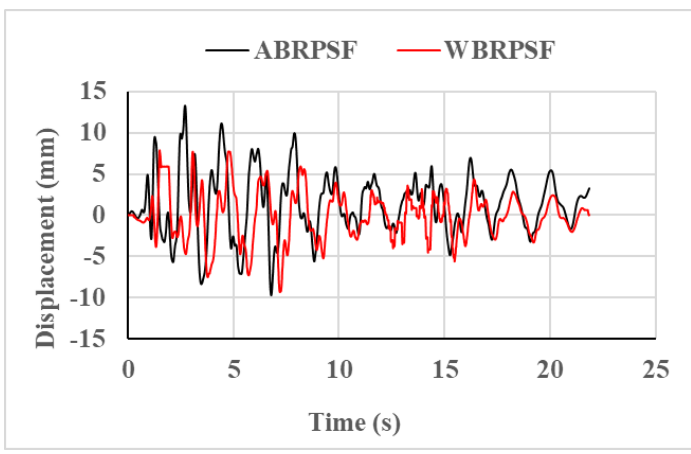

(b) $\mathrm{PGA}=0.20 \mathrm{~g}$ 


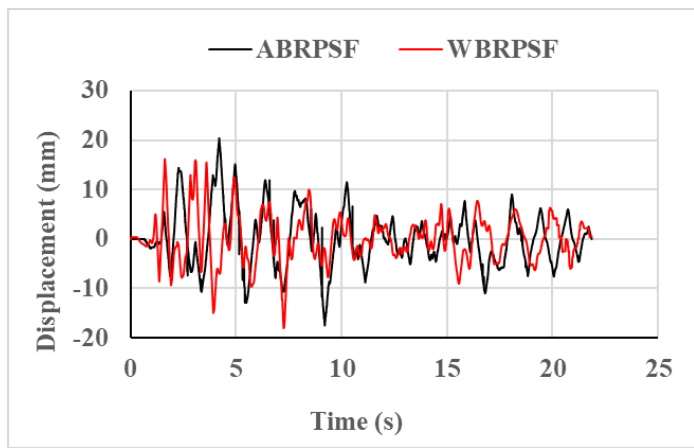

(c) $\mathrm{PGA}=0.40 \mathrm{~g}$

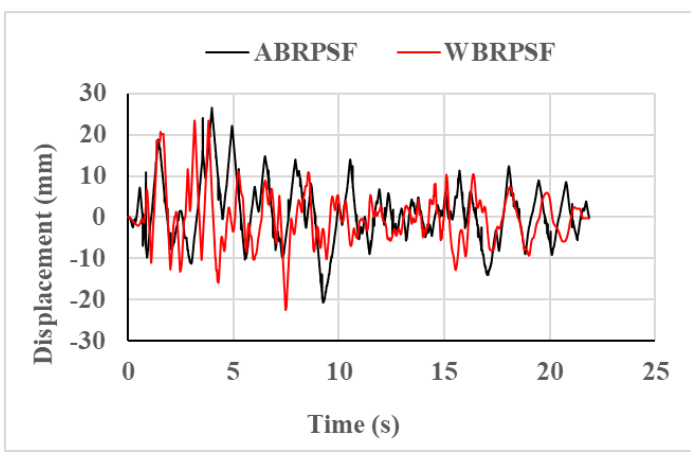

(d) $\mathrm{PGA}=0.51 \mathrm{~g}$

Fig. 13 Time history curves of displacement response under EL-Centro seismic records

Table 3

Displacements and story drifts of WBRPSF and ABRPSF under various seismic levels

\begin{tabular}{|c|c|c|c|c|c|}
\hline \multicolumn{2}{|c|}{ Seismic event } & \multicolumn{2}{|c|}{ Maximum displacement (mm) } & \multicolumn{2}{|c|}{ Maximum story drift } \\
\hline Ground motion & PGA & ABRPSF & WBRPSF & ABRPSF & WBRPSF \\
\hline \multirow{4}{*}{ EL-Centro } & $0.07 \mathrm{~g}$ & 4.95 & 3.74 & $1 / 594$ & $1 / 786$ \\
\hline & $0.20 \mathrm{~g}$ & 13.34 & 9.37 & $1 / 220$ & $1 / 314$ \\
\hline & $0.40 \mathrm{~g}$ & 20.4 & 18.06 & $1 / 144$ & $1 / 163$ \\
\hline & $0.51 \mathrm{~g}$ & 26.6 & 23.36 & $1 / 110$ & $1 / 126$ \\
\hline \multirow{8}{*}{ Wenchuan } & $0.07 \mathrm{~g}$ & 5.67 & 5.56 & $1 / 518$ & $1 / 529$ \\
\hline & $0.20 \mathrm{~g}$ & 17 & 17.21 & $1 / 173$ & $1 / 171$ \\
\hline & $0.40 \mathrm{~g}$ & 34 & 27.96 & $1 / 86$ & $1 / 105$ \\
\hline & $0.51 \mathrm{~g}$ & 43.4 & 36.37 & $1 / 68$ & $1 / 81$ \\
\hline & $0.62 \mathrm{~g}$ & 52.8 & 45.68 & $1 / 56$ & $1 / 65$ \\
\hline & $0.81 \mathrm{~g}$ & 63 & 52.29 & $1 / 47$ & $1 / 56$ \\
\hline & $1.0 \mathrm{~g}$ & 77.4 & 65.05 & $1 / 38$ & $1 / 45$ \\
\hline & $1.2 \mathrm{~g}$ & 103 & 87.69 & $1 / 29$ & $1 / 34$ \\
\hline
\end{tabular}

Figs. 14(a)-(h) show the displacement responses of both steel frames under the Wenchuan seismic records. From PGA $=0.07 \mathrm{~g}$ to $\mathrm{PGA}=0.40 \mathrm{~g}$, the ABRPSF indicated a larger displacement response than the WBRPSF under the same seismic level because the lateral rigidity of the ABRPSF was smaller than that of the WBRPSF. Meanwhile, the displacement responses of both steel frames showed a significant increase under the Wenchuan records compared with that of the EL-Centro records, as shown in Table 3.

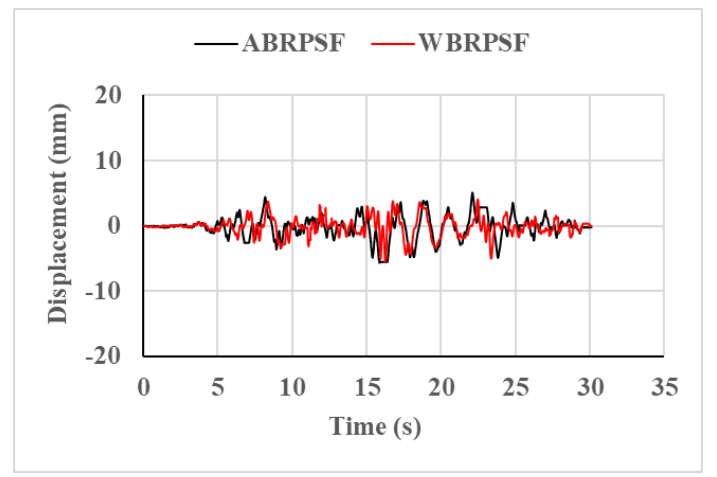

(a) $\mathrm{PGA}=0.07 \mathrm{~g}$

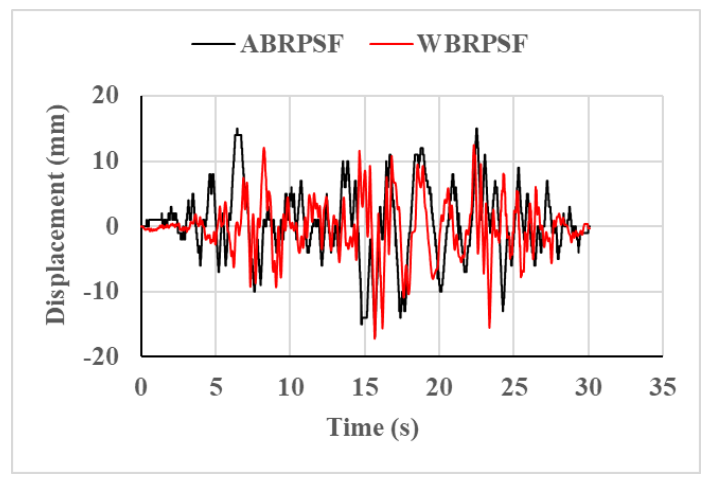

(b) $\mathrm{PGA}=0.20 \mathrm{~g}$ 


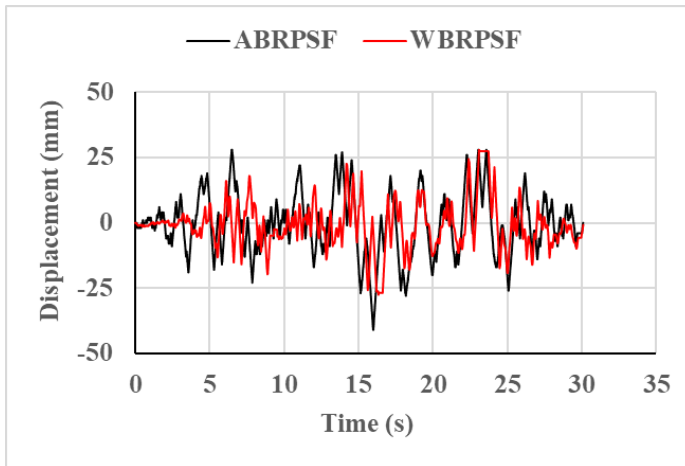

(c) $\mathrm{PGA}=0.40 \mathrm{~g}$

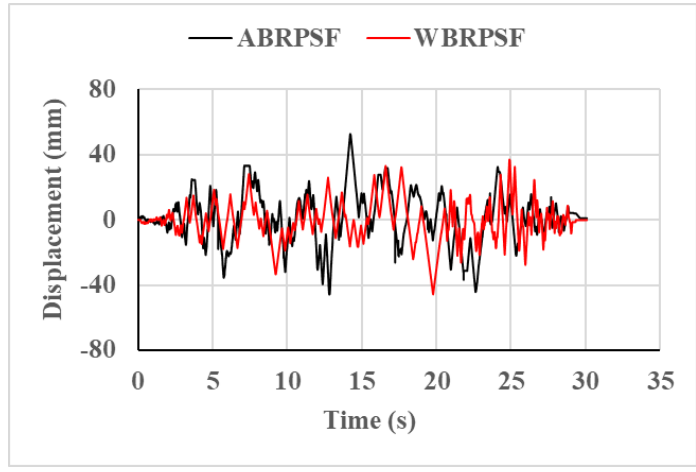

(e) $\mathrm{PGA}=0.62 \mathrm{~g}$

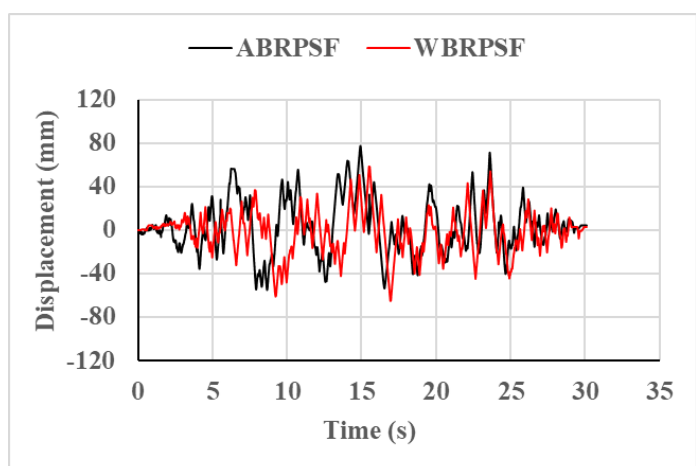

(g) PGA $=1.0 \mathrm{~g}$

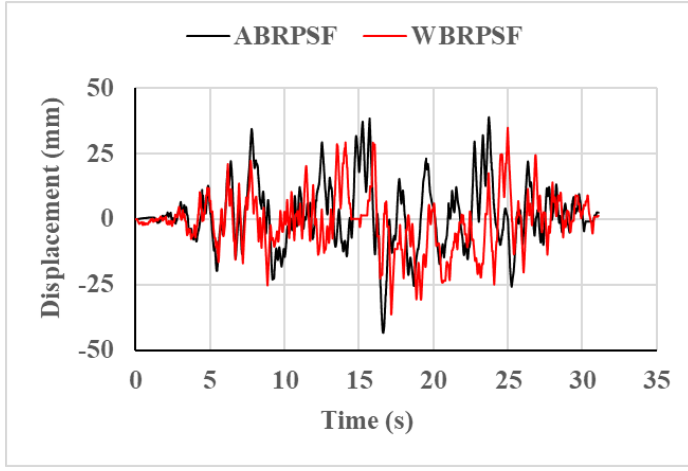

(d) $P G A=0.51 \mathrm{~g}$

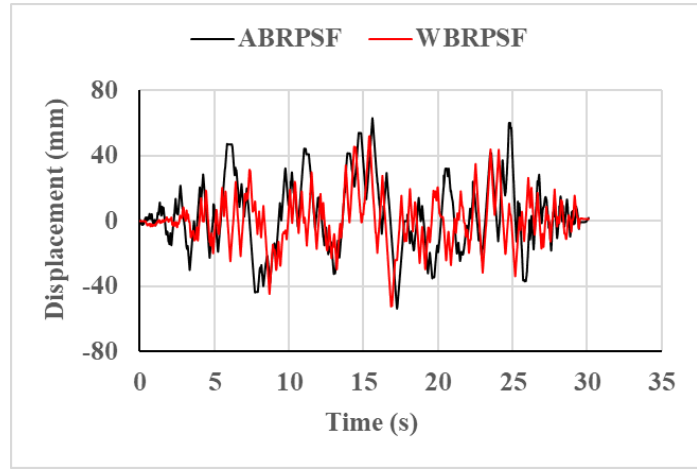

(f) $\mathrm{PGA}=0.81 \mathrm{~g}$

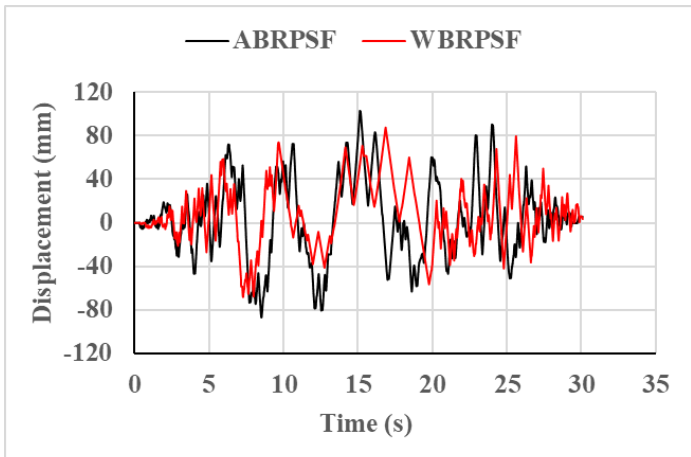

(h) $P G A=1.2 \mathrm{~g}$

Fig. 14 Time history curves of displacement response under Wenchuan seismic records

When the seismic level reached PGA $=0.51 \mathrm{~g}$, as shown in Figs. 14(d)-(h) and Table 3, the variation trends of displacement responses of the ABRPSF and WBRPSF were similar, whereas that of the ABRPSF showed larger values under the same seismic event. To study the seismic performances of both steel frames under higher seismic levels, the ground motion records of Wenchuan with PGAs of $0.62,0.81,1.0$, and $1.2 \mathrm{~g}$ were input to the testing equipment. When PGA $=0.62 \mathrm{~g}$, the maximum displacement responses of the ABRPSF and WBRPSF reached $51.8 \mathrm{~mm}(1 / 56 \mathrm{rad})$ and $45.68 \mathrm{~mm}(1 / 65 \mathrm{rad})$, which revealed a $13.4 \%$ increase in the maximum displacement response of the ABRPSF. When PGA increased to $0.81 \mathrm{~g}$, the maximum displacement responses were $63 \mathrm{~mm}$ $(1 / 47 \mathrm{rad})$ and $52.29 \mathrm{~mm}(1 / 56 \mathrm{rad})$ for the ABRPSF and WBRPSF, respectively, and the corresponding increment was $20.5 \%$, the maximum story drifts exceeded the elastic story drift limit of $1 / 50$, but the frames can return to their original positions after an earthquake. With the increase in the seismic level, the difference between both steel frames fluctuated within $20 \%$. When the PGA reached $1.0 \mathrm{~g}$, the maximum displacements of the ABRPSF and WBRPSF were $77.4 \mathrm{~mm}(1 / 38 \mathrm{rad})$ and $65.05 \mathrm{~mm}(1 / 45 \mathrm{rad})$, respectively. When the PGA increased to $1.2 \mathrm{~g}$, the maximum displacements were $103 \mathrm{~mm}(1 / 29 \mathrm{rad})$ and $87.69 \mathrm{~mm}(1 / 34 \mathrm{rad})$ for the ABRPSF and WBRPSF, respectively, and the growth rates were $18.98 \%$ and $17.46 \%$, respectively. Therefore, it can be concluded that under the EL-Centro and Wenchuan seismic records, the displacement responses for the ABRPSF and WBRPSF reflected a similar variation trend, and the improved ABRPSF indicated a larger response because its lateral rigidity was less than that of the WBRPSF.

\subsection{Gap opening}

Studies regarding the gap opening conditions between the long and short beam portions of the ABRPSF and WBRPSF can be classified into two cases: one is the push direction of the loading equipment and the other is the pull direction. Because the actuator was installed on one end of the steel frame, the asymmetrical loading setup will cause diverse results to the gap opening of the steel frame under different loading directions. All data pertaining to the gap openings were measured using micro displacement meters fixed to the interface between the short and long beam portions. Figs. 15 and 16 show the gap opening photographs of both steel frames in the pull direction under the EL-Centro and Wenchuan seismic records. 


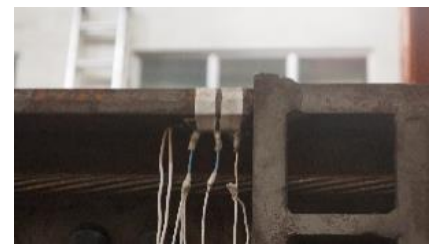

Maximum gap opening rotation $0.04 \%$

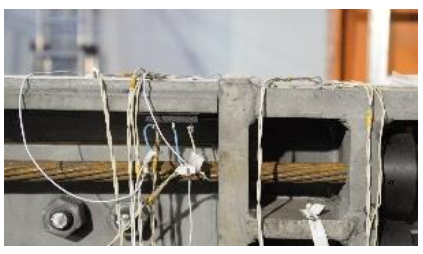

Maximum gap opening rotation $0.03 \%$

(a) $\mathrm{PGA}=0.07 \mathrm{~g}$

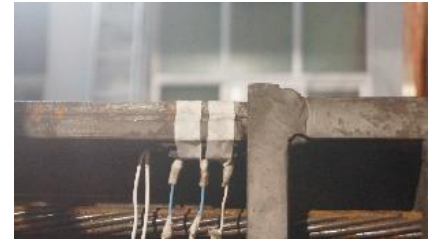

Maximum gap opening rotation $0.14 \%$

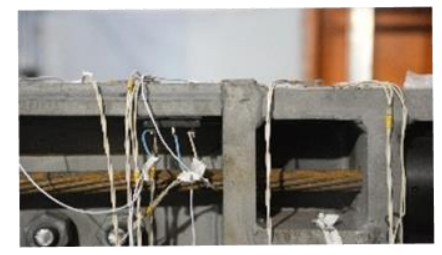

Maximum gap opening rotation $0.21 \%$

ABRPSF

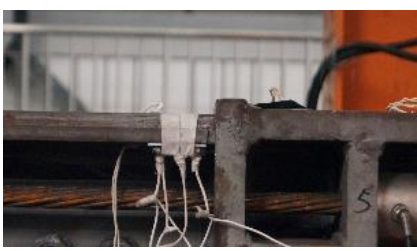

Maximum gap opening rotation $0.06 \%$

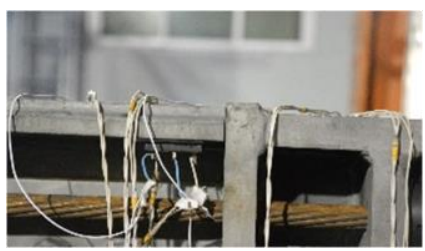

Maximum gap opening rotation $0.07 \%$

ABRPSF

WBRPSF

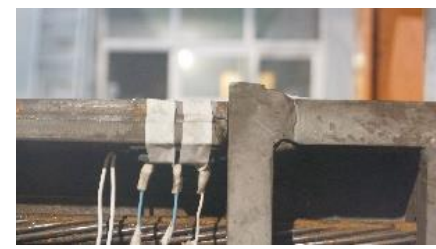

Maximum gap opening rotation $0.16 \%$

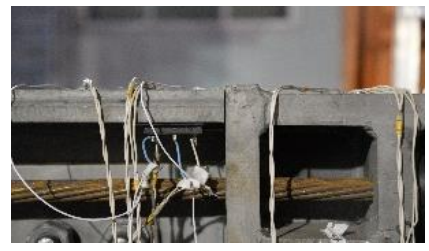

Maximum gap opening rotation $0.32 \%$ WBRPSF

(c) $\mathrm{PGA}=0.40 \mathrm{~g}$

(d) $\mathrm{PGA}=0.51 \mathrm{~g}$

Fig. 15 Gap opening photographs of both steel frames in pull direction under EL-Centro seismic records

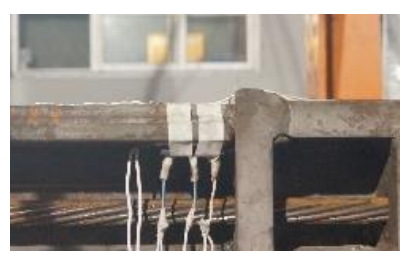

Maximum gap opening rotation $0.03 \%$

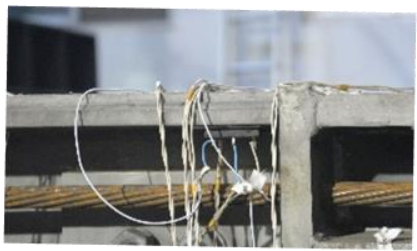

Maximum gap opening rotation $0.05 \%$

(a) $\mathrm{PGA}=0.07 \mathrm{~g}$

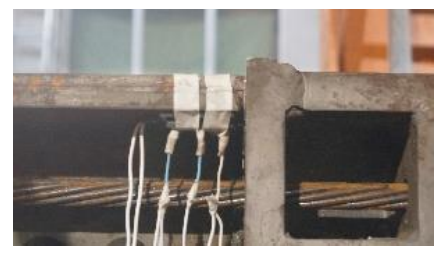

ABRPSF

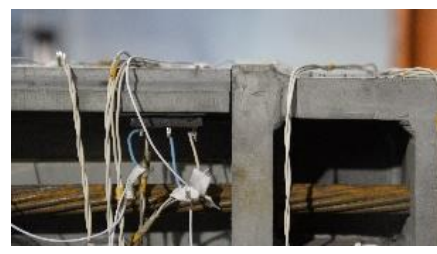

WBRPSF

Maximum gap opening rotation $0.12 \% \quad$ Maximum gap opening rotation $0.38 \%$

(a) $\mathrm{PGA}=0.40 \mathrm{~g}$

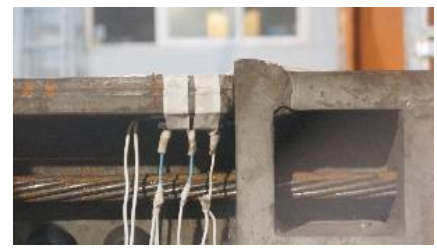

Maximum gap opening rotation $0.38 \%$

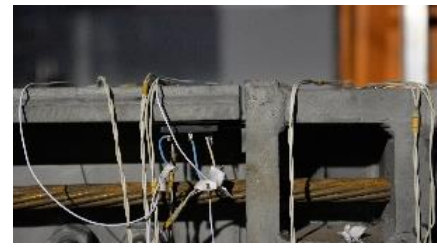

Maximum gap opening rotation $1.23 \%$

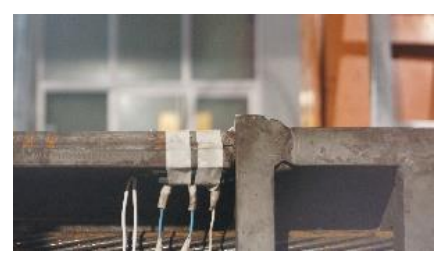

Maximum gap opening rotation $0.12 \%$

ABRPSF

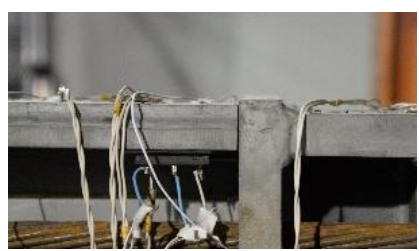

Maximum gap opening rotation $0.21 \%$

WBRPSF

(b) $\mathrm{PGA}=0.20 \mathrm{~g}$

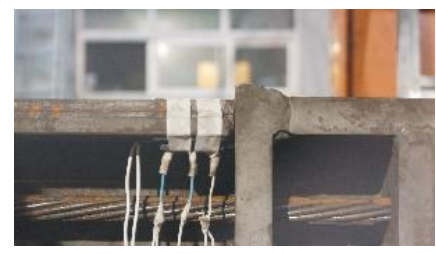

ABRPSF

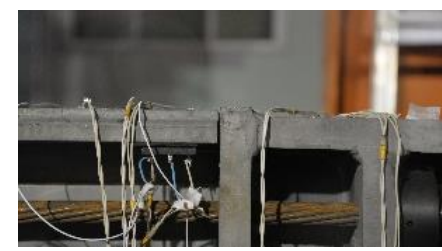

WBRPSF

Maximum gap opening rotation $0.26 \% \quad$ Maximum gap opening rotation $0.58 \%$ (b) $\mathrm{PGA}=0.51 \mathrm{~g}$

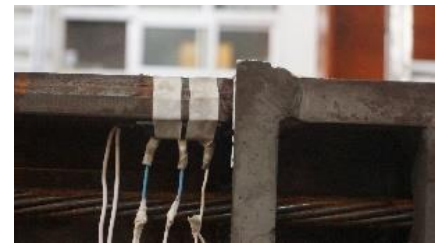

Maximum gap opening rotation $0.40 \%$

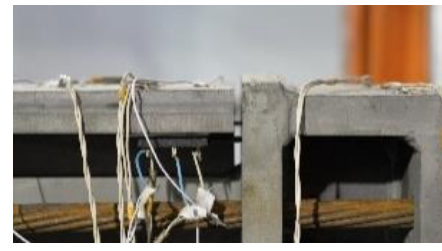

Maximum gap opening rotation $1.38 \%$

ABRPSF 


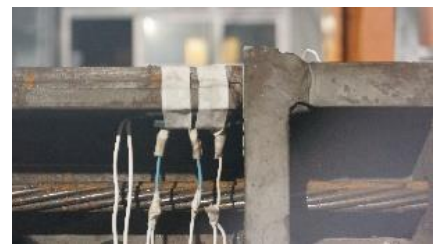

Maximum gap opening rotation $0.45 \%$ ABRPSF

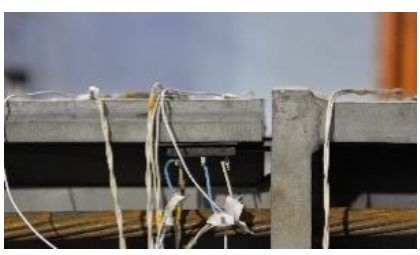

Maximum gap opening rotation 1.68\% WBRPSF

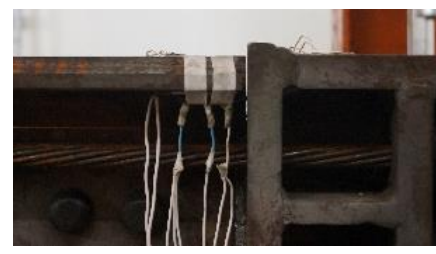

Maximum gap opening rotation $0.48 \%$ ABRPSF

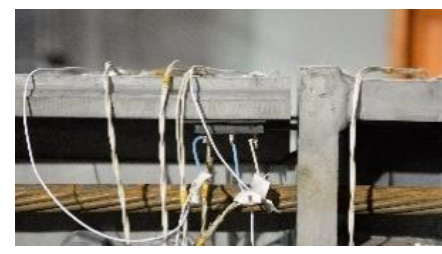

Maximum gap opening rotation $1.96 \%$ WBRPSF

(a) $\mathrm{PGA}=1.0 \mathrm{~g}$

(b) $\mathrm{PGA}=1.2 \mathrm{~g}$

Fig. 16 Gap opening photographs of both steel frames in pull direction under Wenchuan seismic records

The gap opening data of the ABRPSF and WBRPSF under EL-Centro and Wenchuan seismic records are listed in Table 4. As shown, the WBRPSF showed a larger gap opening than the ABRPSF. As the seismic level increased, the increasing trend of the gap opening of the ABRPSF and WBRPSF under the EL-Centro and Wenchuan records became clearer. Under the same seismic level, the gap opening of the ABRPSF was smaller than that of the WBRPSF. The residual gap openings of both steel frames were extremely small, as shown in Table 4.

Therefore, it can be concluded that under the EL-Centro and Wenchuan seismic records, the gap openings of the ABRPSF and WBRPSF showed similar variation trends, and the improved ABRPSF demonstrated a smaller response due to the bolt slippage that occurred on the beam-to-column connection of the
ABRPSF. When the PGA reached $0.62 \mathrm{~g}$, which corresponds to a 9-degree rare earthquake according to the Chinese Code for Seismic Design of Buildings (GB 50011-2010, 2016) under the Wenchuan seismic records, the maximum story drifts of the ABRPSF and WBRPSF reached 1/56 and 1/65 rad, respectively, which were less than the elastic story drift of $1 / 50 \mathrm{rad}$; additionally, the residual gap opening rotation was small, implying that both frames exhibited excellent self-centering capability. When PGA $=1.2 \mathrm{~g}$ under the Wenchuan seismic record, the maximum story drifts of the ABRPSF and WBRPSF were 1/29 and 1/34, respectively, which exceeded the elastic story drift of $1 / 50 \mathrm{rad}$; however, the residual gap opening rotation was $0.00 \%$, indicating that both steel frames had relatively good opening and closing mechanisms and that their self-centering performances were good.

Table 4

Residual gap opening rotation of both steel frames under various seismic levels

\begin{tabular}{|c|c|c|c|c|c|}
\hline \multirow{2}{*}{ Seismic record } & \multirow{2}{*}{ Seismic level } & \multicolumn{2}{|c|}{ Maximum gap opening rotation } & \multicolumn{2}{|c|}{ Residual gap opening rotation } \\
\hline & & ABRPSF & WBRPSF & ABRPSF & WBRPSF \\
\hline \multirow{4}{*}{ EL-Centro } & $\mathrm{PGA}=0.07 \mathrm{~g}$ & $0.04 \%$ & $0.03 \%$ & $0.00 \%$ & $0.00 \%$ \\
\hline & $\mathrm{PGA}=0.20 \mathrm{~g}$ & $0.06 \%$ & $0.07 \%$ & $0.00 \%$ & $0.01 \%$ \\
\hline & $\mathrm{PGA}=0.40 \mathrm{~g}$ & $0.14 \%$ & $0.21 \%$ & $0.01 \%$ & $0.03 \%$ \\
\hline & $\mathrm{PGA}=0.51 \mathrm{~g}$ & $0.16 \%$ & $0.32 \%$ & $0.02 \%$ & $0.07 \%$ \\
\hline \multirow{8}{*}{ Wenchuan } & $\mathrm{PGA}=0.07 \mathrm{~g}$ & $0.03 \%$ & $0.05 \%$ & $0.01 \%$ & $0.00 \%$ \\
\hline & $\mathrm{PGA}=0.20 \mathrm{~g}$ & $0.12 \%$ & $0.21 \%$ & $0.00 \%$ & $0.13 \%$ \\
\hline & $\mathrm{PGA}=0.40 \mathrm{~g}$ & $0.12 \%$ & $0.38 \%$ & $0.00 \%$ & $0.06 \%$ \\
\hline & $\mathrm{PGA}=0.51 \mathrm{~g}$ & $0.26 \%$ & $0.58 \%$ & $0.00 \%$ & $0.02 \%$ \\
\hline & $\mathrm{PGA}=0.62 \mathrm{~g}$ & $0.38 \%$ & $1.23 \%$ & $0.00 \%$ & $0.01 \%$ \\
\hline & $\mathrm{PGA}=0.81 \mathrm{~g}$ & $0.40 \%$ & $1.38 \%$ & $0.00 \%$ & $0.01 \%$ \\
\hline & $\mathrm{PGA}=1.0 \mathrm{~g}$ & $0.45 \%$ & $1.68 \%$ & $0.12 \%$ & $0.02 \%$ \\
\hline & $\mathrm{PGA}=1.2 \mathrm{~g}$ & $0.48 \%$ & $1.96 \%$ & $0.00 \%$ & $0.00 \%$ \\
\hline
\end{tabular}

\subsection{Hysteretic behavior}

Figs. 17(a)-(d) show a comparison of hysteretic curves between the WBRPSF and ABRPSF under the EL-Centro seismic records. Based on the figures, we concluded that the lateral rigidity and carrying capacity of the ABRPSF were slightly lower than those of the WBRPSF, whereas the ductility of the ABRPSF exceeded that of the WBRPSF. When the seismic action reached the frequent earthquake level with $\mathrm{PGA}=0.07 \mathrm{~g}$, the maximum story drifts of the ABRPSF and WBRPSF were 1/594 and 1/786 rad, respectively, which were less than the story drift limit of $1 / 250 \mathrm{rad}$ according to the Code for Seismic Design of Buildings, and the hysteretic curves were linear. When the loading level reached those of fortification earthquakes with PGA $=0.20 \mathrm{~g}$, the maximum story drifts of the ABRPSF and WBRPSF were $1 / 220$ and 1/314, respectively, and hysteretic loops began to appear because the gap opening of both steel frames and the web friction device dissipated energy; consequently, both steel frames were in the elastic state. When the PGA reached 0.40 and $0.51 \mathrm{~g}$, as shown in Figs. 17(c)-(d), clear hysteretic loops appeared for the ABRPSF and WBRPSF. When the PGA reached $0.51 \mathrm{~g}$, the maximum story drifts were $1 / 110$ and $1 / 126 \mathrm{rad}$, which were less than the story drift limit of $1 / 50$ rad according to the Code for Seismic Design of Buildings . The hysteretic loops formed completely, and the energy dissipation was more evident. In each loading process, the structural carrying capacity for the WBRPSF was higher than that for the ABRPSF, but the latter yielded a more satisfying deformation behavior and energy dissipation. Additionally, both frames can return to their original positions after an earthquake, thereby demonstrating their good selfcentering behaviors. 


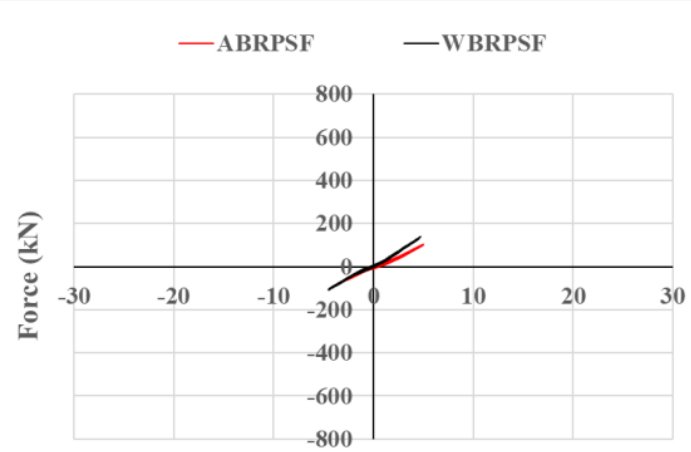

Story drift $(\mathbf{m m})$

(a) $\mathrm{PGA}=0.07 \mathrm{~g}$

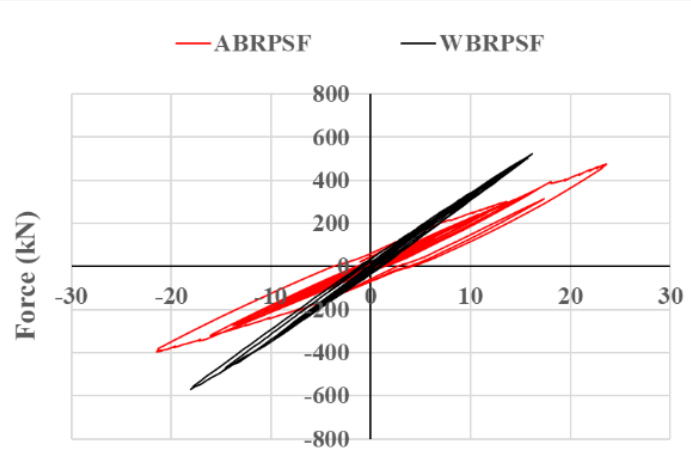

Story drift $(\mathrm{mm})$

(c) $\mathrm{PGA}=0.40 \mathrm{~g}$

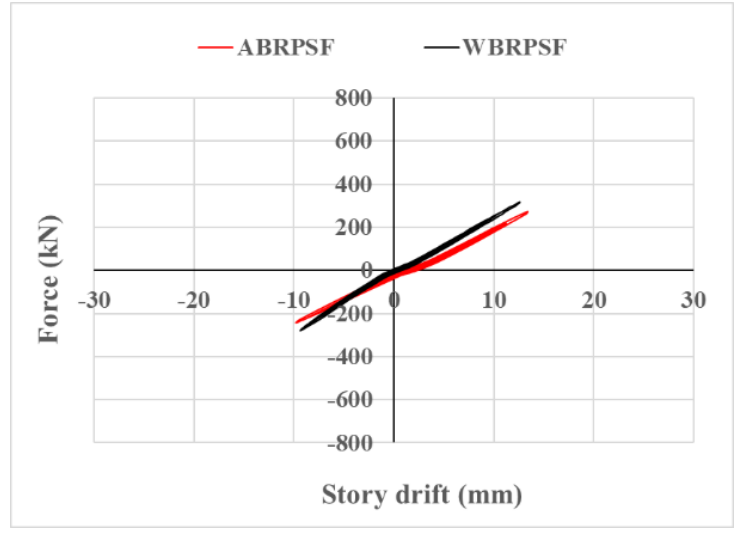

(b) $\mathrm{PGA}=0.20 \mathrm{~g}$

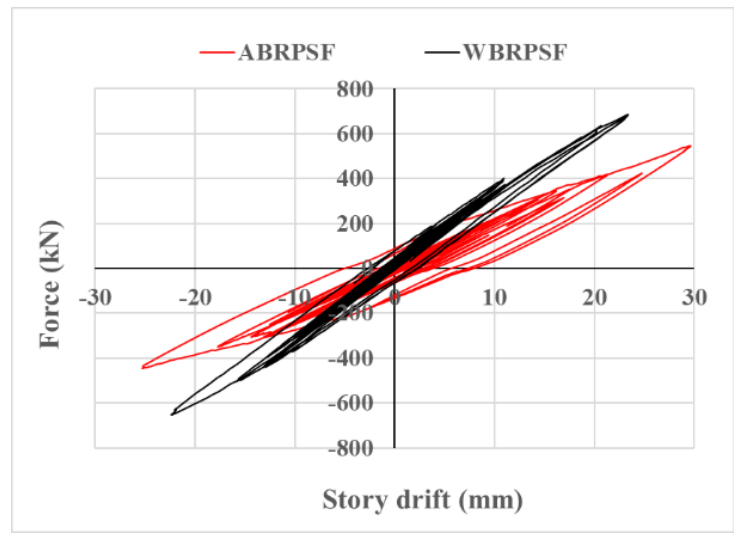

(d) $\mathrm{PGA}=0.51 \mathrm{~g}$

Fig. 17 Hysteretic curves of WBRPSF and ABRPSF under EL-Centro seismic records

Figs. 18(a)-(h) show the hysteretic curves of floor shear and displacement for the ABRPSF and WBRPSF under the Wenchuan seismic records. When PGA $=0.07 \mathrm{~g}$, the maximum story drifts of the ABRPSF and WBRPSF were $1 / 518$ and 1/529 rad, respectively, which were less than the story drift limit of $1 / 250 \mathrm{rad}$ according to the Code for Seismic Design of Buildings . The floor shear and displacement of both steel frames maintained a linear relationship, and the lateral rigidity of the ABRPSF was slightly lower than that of the WBRPSF. When PGA $=0.2 \mathrm{~g}$, the maximum story drifts of the ABRPSF and WBRPSF were $1 / 173$ and $1 / 171 \mathrm{rad}$, respectively, and hysteretic loops began appearing. When the seismic level reached $0.62 \mathrm{~g}$, the maximum story drifts reached 1/56 and 1/65 rad for the ABRPSF and WBRPSF, respectively, which were less than the story drift limit of 1/50 rad according to the Code for Seismic Design of Buildings . The hysteretic loops for both steel frames became more evident. Furthermore, an abrupt change appeared in the hysteretic curves of the WBRPSF, which was mainly caused by the slippage of the column foot. At PGA $=0.81,1.0$, and $1.2 \mathrm{~g}$, the enclosed area of the hysteretic loops for both steel frames continued to increase, and the maximum story drift reached $1 / 29$ and $1 / 34 \mathrm{rad}$ for the ABRPSF and WBRPSF when PGA $=1.2 \mathrm{~g}$, respectively. Although the maximum story drifts exceeded the elastic story drifts limit $(1 / 50$ rad) defined in the Code for Seismic Design of Buildings , both frames can still return to their original positions after an earthquake. Both steel frames demonstrated a satisfactory energy dissipation capacity owing to the web friction devices; however, the ABRPSF demonstrated a more satisfactory energy dissipation capacity because of the energy dispassion of bolt slippage on the beam-to-column connection.

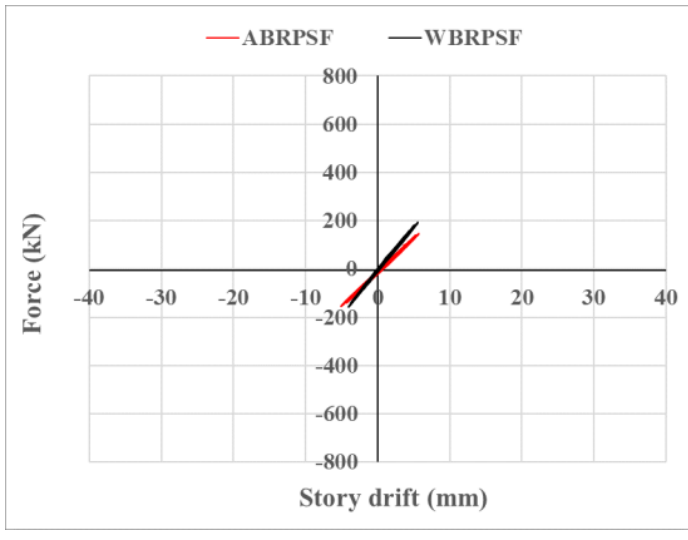

(a) $\mathrm{PGA}=0.07 \mathrm{~g}$

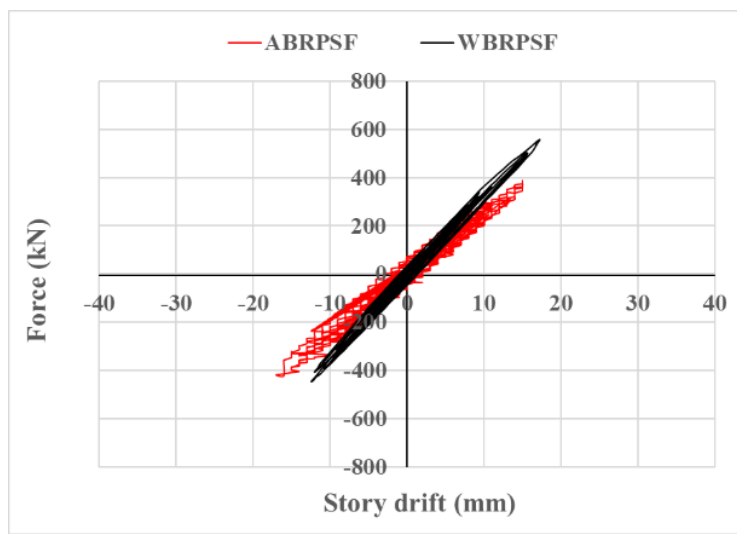

(b) $\mathrm{PGA}=0.20 \mathrm{~g}$ 


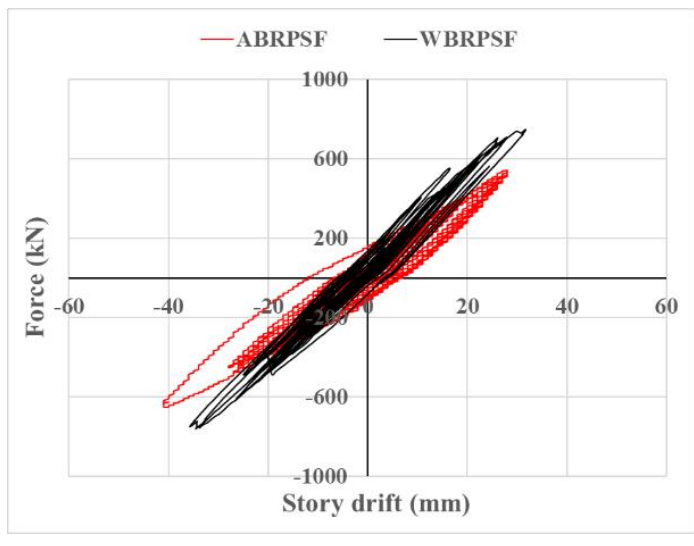

(c) $\mathrm{PGA}=0.40 \mathrm{~g}$

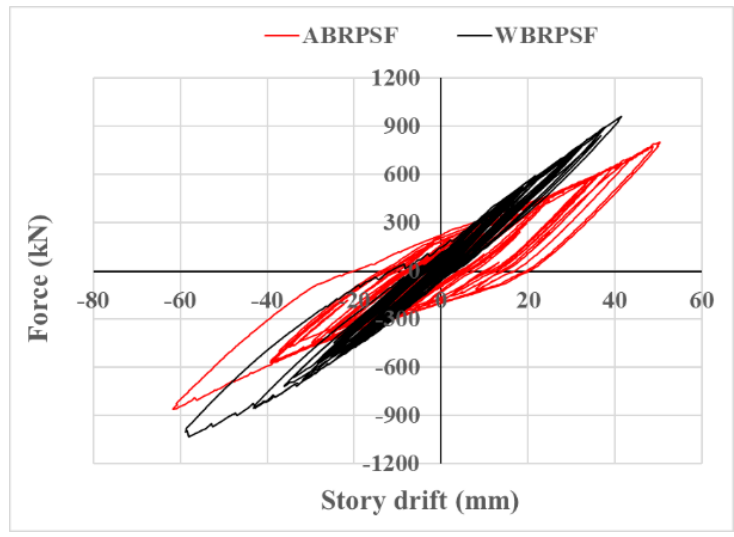

(e) $\mathrm{PGA}=0.62 \mathrm{~g}$

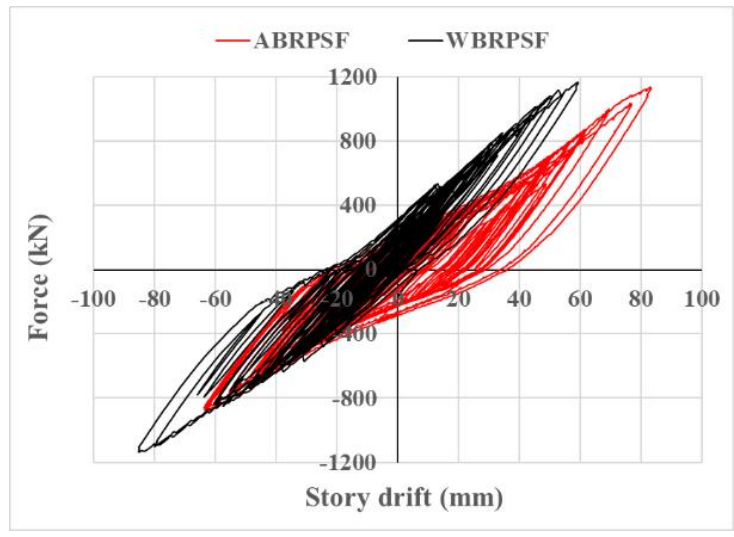

(g) $\mathrm{PGA}=1.0 \mathrm{~g}$

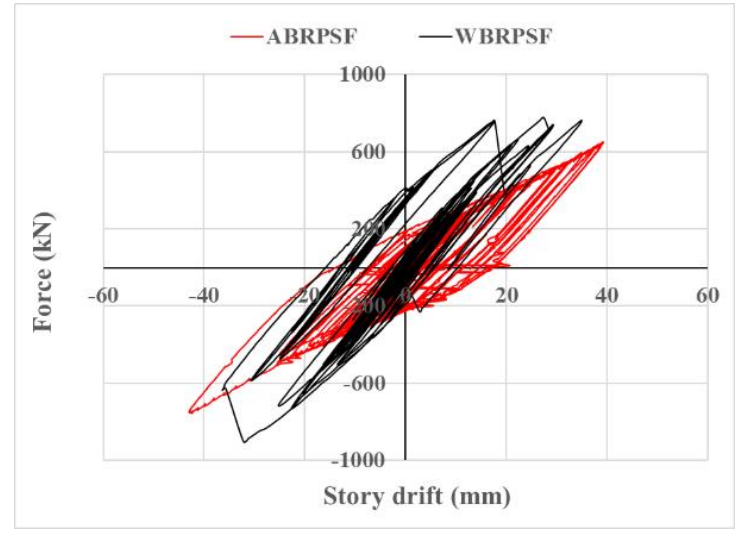

(d) $\mathrm{PGA}=0.51 \mathrm{~g}$

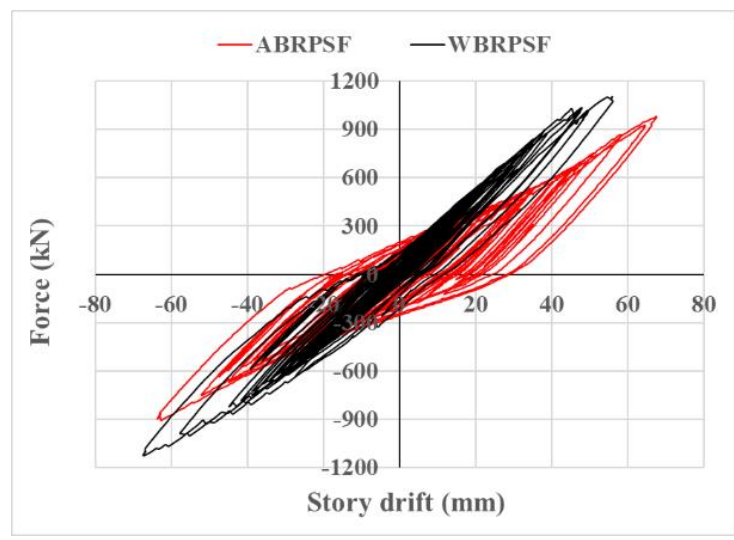

(f) $\mathrm{PGA}=0.81 \mathrm{~g}$

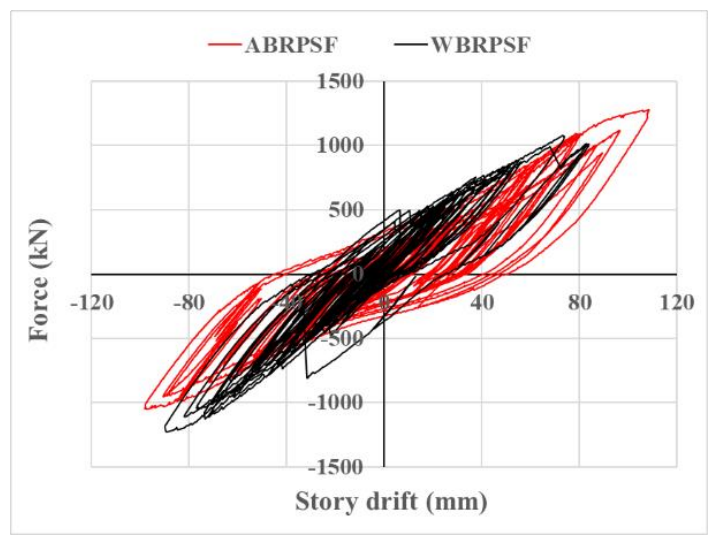

(h) $\mathrm{PGA}=1.2 \mathrm{~g}$

Fig. 18 Hysteretic curves of ABRPSF and WBRPSF under Wenchuan ground motion records

\subsection{Strain development}

Comparative results pertaining to the strain development of the typical regions of the ABRPSF and WBRPSF under fortification and rare seismic actions are shown in Figs. 19 and 20. The yield strain $\varepsilon_{\mathrm{y}}$ adopted in this study was $1800 \mu \varepsilon$, which was obtained based on the completed material test. The strain gauge was used to measure the largest strain for each position. The column foot investigated in this study represented the peak strain value on the column foot flange; column base flange, which is the flange of the column parallel to the altitude of the beam; panel zone, which is the column web plate in the area of the beam-to-column connection; flanges of the short and long beams, which were in the upper flange area closer to the vertical plate; and the upper surface of the reinforced plate of the long beam that was closer to the vertical plate.
The comparative time history curves of strain variation for both steel frames under 0.20 and $0.51 \mathrm{~g}$ of the EL-Centro seismic records are shown in Figs. 19 and 20, respectively. Furthermore, Table 5 lists the detailed data for strain development. As shown in the figures, the strain for both steel frames was at the same level and remained at a relatively low level apart from the reinforced plate. Moreover, the strain developments of the column foot and column base flanges of the WBRPSF was larger than that of the ABRPSF. Meanwhile, the peak strain appeared at the reinforced plate of the ABRPSF, which reached $1132.7 \mu \varepsilon$ and was still below the yield level. When PGA $=0.51 \mathrm{~g}$, the maximum story drifts of the ABRPSF and WBRPSF were 1/110 and 1/126 rad, which were less than the elastic story drift limit of 1/50 rad according to the Code for Seismic Design of Buildings . Furthermore, both steel frames remained at an elastic state upon unloading under the EL-Centro records. 


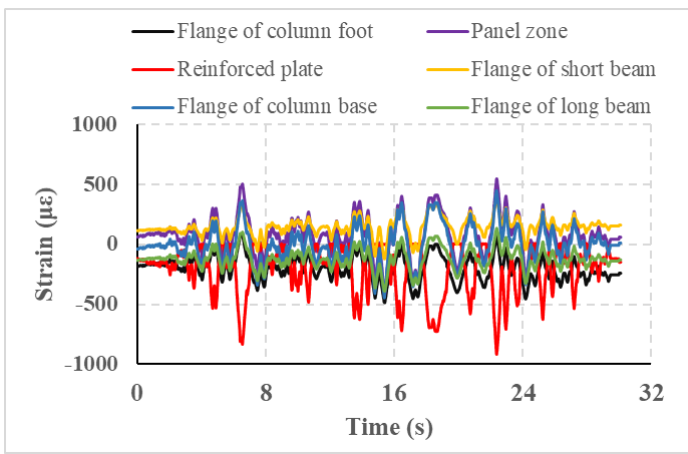

(a) ABRPSF

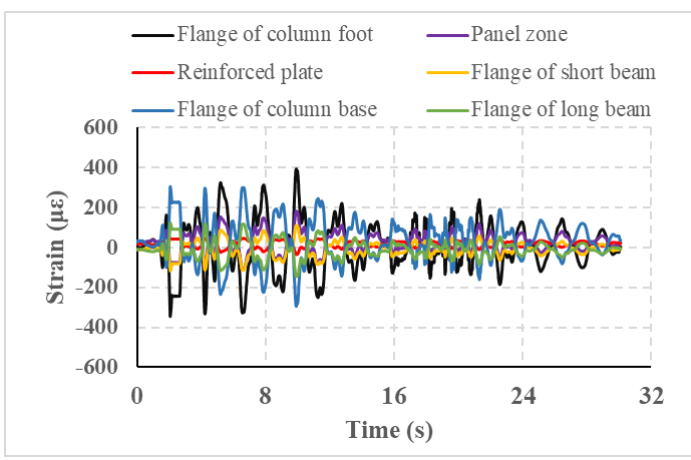

(b) WBRPSF

Fig. 19 Time history curves of strain development under EL-Centro seismic records (PGA $=0.20 \mathrm{~g}$ )

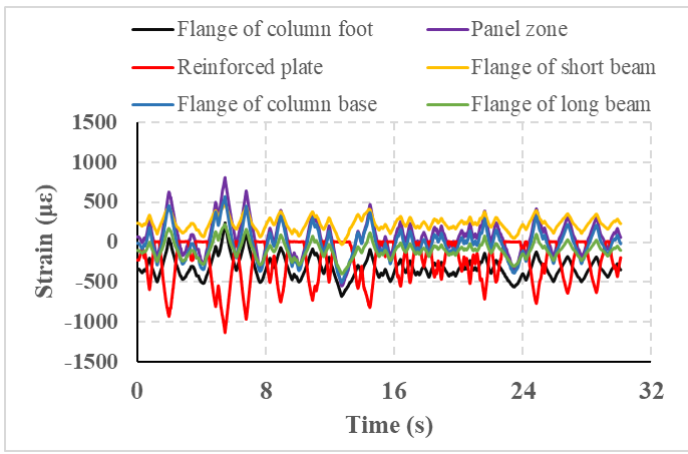

(a) ABRPSF

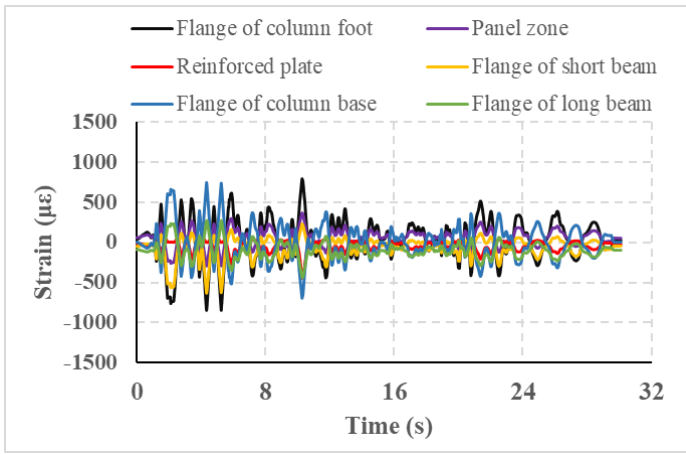

(b) WBRPSF

Fig. 20 Time history curves of strain development under EL-Centro seismic records (PGA $=0.51 \mathrm{~g}$ )

Table 5

Strain development at typical regions for both steel frames under EL-Centro seismic records

\begin{tabular}{|c|c|c|c|c|c|c|c|c|}
\hline Steel frames & PGA & Flange of column foot & Panel zone & Reinforced plate & Flange of short beam & Flange of column base & Big L plate & Small L plate \\
\hline \multirow{4}{*}{ ABRPSF } & $0.07 \mathrm{~g}$ & 211.1 & 155.4 & 4.8 & 115.7 & 111.8 & 131.3 & 68.4 \\
\hline & $0.20 \mathrm{~g}$ & 390.4 & 435.3 & 776.7 & 318.5 & 328.8 & 246.9 & 284.8 \\
\hline & $0.40 \mathrm{~g}$ & 580.3 & 700 & 1031.3 & 451 & 586.2 & 484.9 & 553.4 \\
\hline & $0.51 \mathrm{~g}$ & 678.3 & 808.7 & 1132.7 & 495.9 & 571.8 & 630.1 & 721.1 \\
\hline \multirow{4}{*}{ WBRPSF } & $0.07 \mathrm{~g}$ & 373.2 & 93.9 & 30.1 & 64.9 & 187.7 & - & - \\
\hline & $0.20 \mathrm{~g}$ & 440.7 & 199.5 & 38.9 & 170.2 & 813.0 & - & - \\
\hline & $0.40 \mathrm{~g}$ & 815.8 & 304.3 & 195.7 & 352.5 & 353.6 & - & - \\
\hline & $0.51 \mathrm{~g}$ & 847.4 & 368.2 & 446.3 & 632.3 & 746.4 & - & - \\
\hline
\end{tabular}

Figs. 21-26 show the strain development of typical positions of both steel records, and the detailed data are shown in Table 6. frames under $0.20,0.40,0.62,0.81,1.0$, and $1.2 \mathrm{~g}$ of the Wenchuan seismic

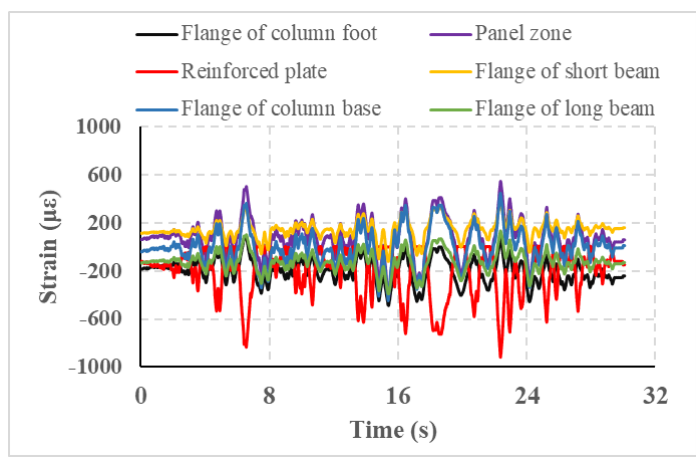

(a) ABRPSF

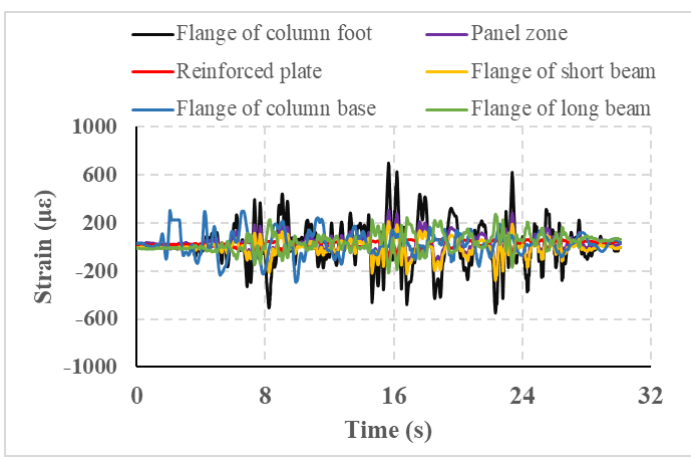

(b) WBRPSF

Fig. 21 Time history curves of strain development under Wenchuan seismic records (PGA $=0.20 \mathrm{~g}$ ) 


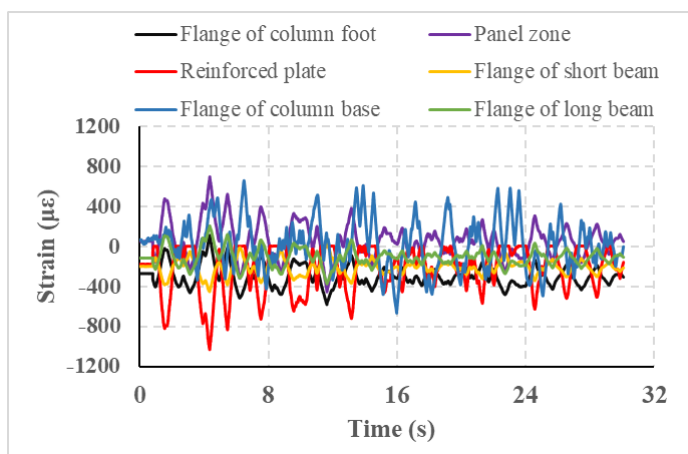

(a) ABRPSF

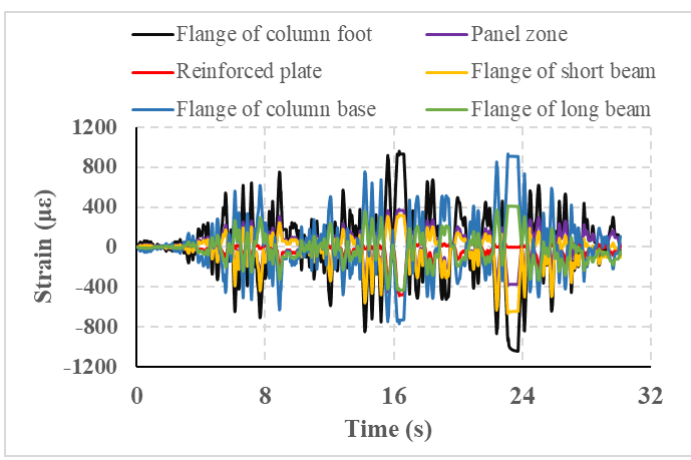

(b) WBRPSF

Fig. 22 Time history curves of strain development under Wenchuan seismic records (PGA $=0.40 \mathrm{~g}$ )

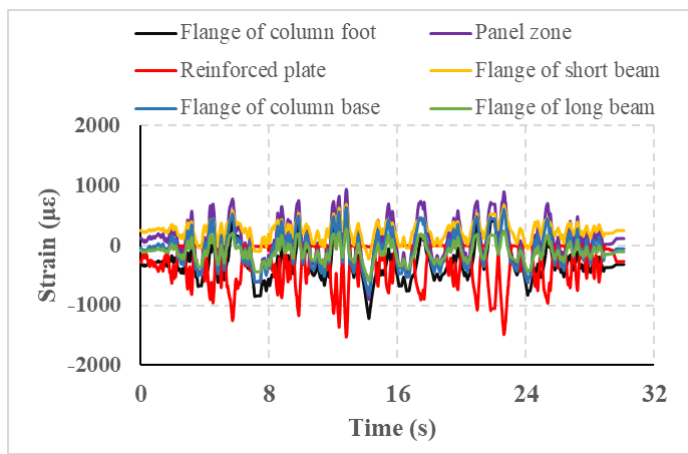

(a) ABRPSF

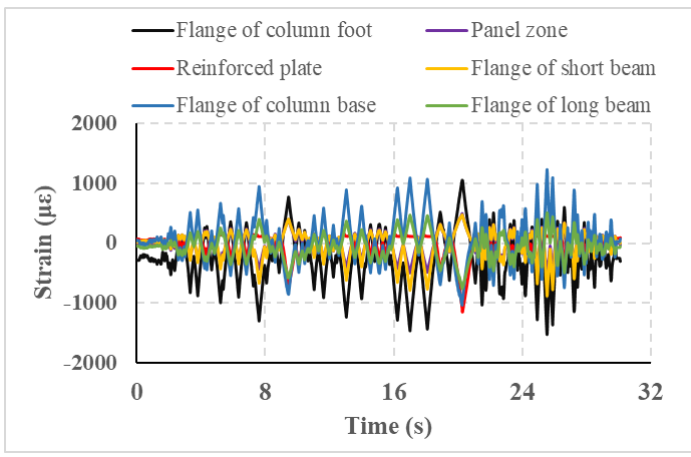

(b) WBRPSF

Fig. 23 Time history curves of strain development under Wenchuan seismic records (PGA $=0.62 \mathrm{~g}$ )

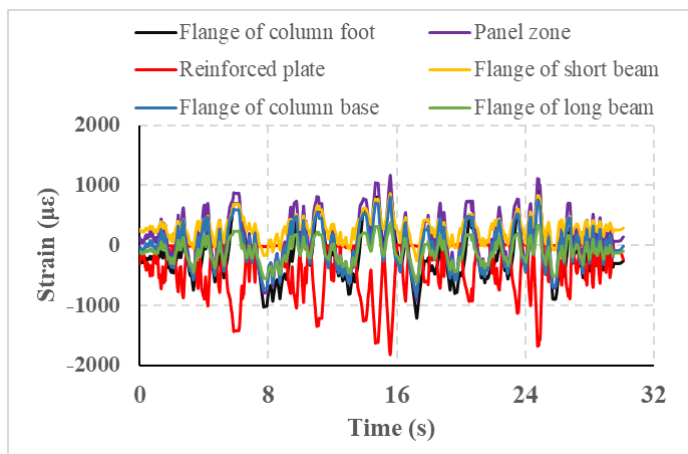

(a) ABRPSF

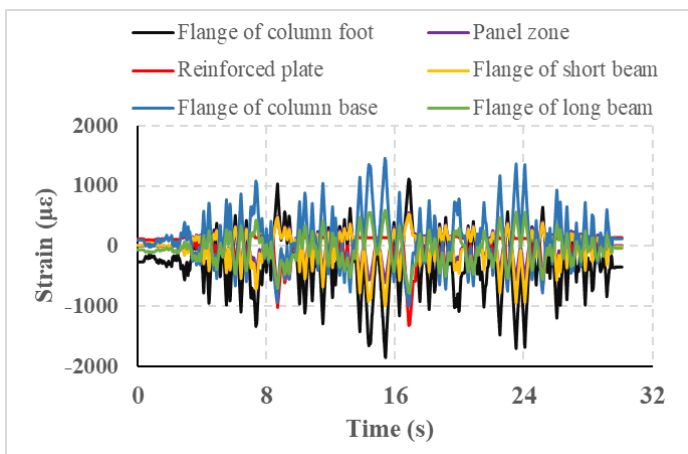

(b) WBRPSF

Fig. 24 Time history curves of strain development under Wenchuan seismic records $(\mathrm{PGA}=0.81 \mathrm{~g})$

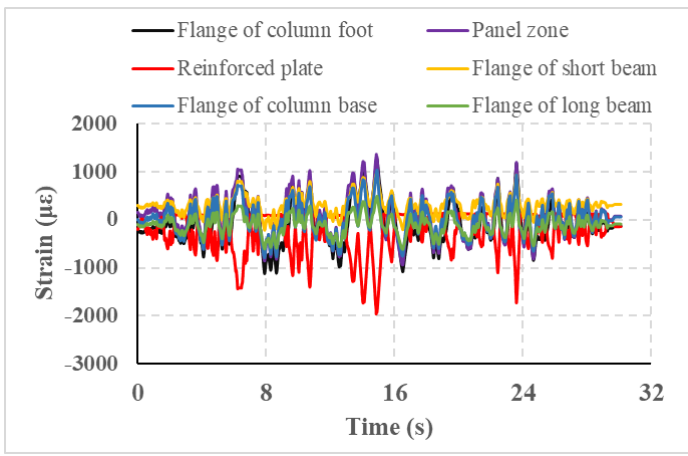

(a) ABRPSF

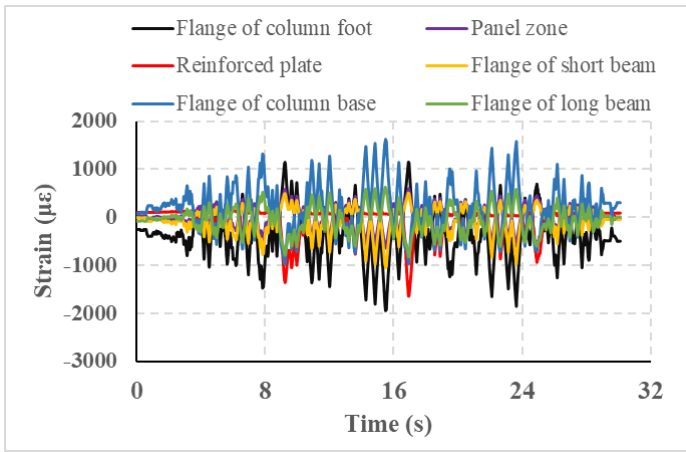

(b) WBRPSF

Fig. 25 Time history curves of strain development under Wenchuan seismic records ( $\mathrm{PGA}=1.0 \mathrm{~g}$ ) 


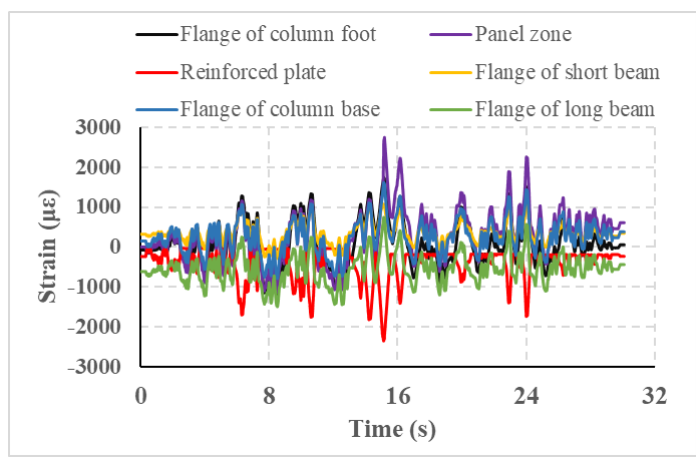

(a) ABRPSF

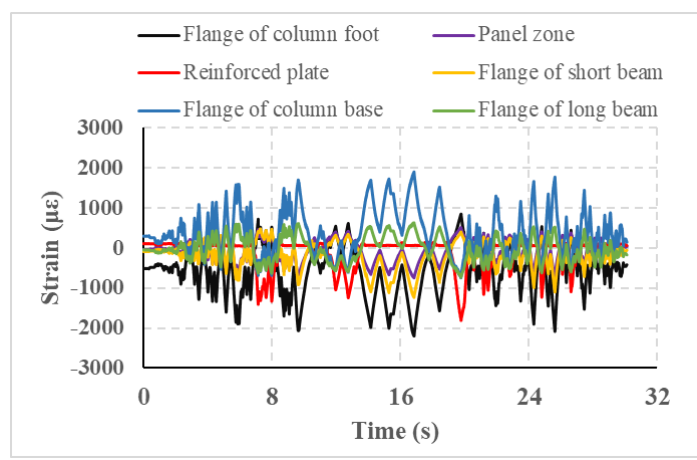

(b) WBRPSF

Fig. 26 Time history curves of strain development under Wenchuan seismic records (PGA $=1.2 \mathrm{~g}$ )

When the PGA reached $0.62 \mathrm{~g}$, the maximum story drifts of the ABRPSF and WBRPSF were $1 / 56$ and $1 / 65 \mathrm{rad}$, respectively, whereas the maximum strains were $1529.5 \mu \varepsilon$ and $1522.9 \mu \varepsilon$, respectively. Both steel frames still remained in an elastic state and exhibited good recentering capacities. When PGA $=0.81 \mathrm{~g}$, the maximum story drifts of the ABRPSF and WBRPSF were $1 / 47$ and $1 / 56 \mathrm{rad}$, respectively; plasticity started to develop for both steel frames, and they were still in the same level. The column foot flange of the WBRPSF entered the plastic state but the column foot flange of the ABRPSF remained elastic. When $\mathrm{PGA}=1.2 \mathrm{~g}$, the maximum story drifts of the ABRPSF and WBRPSF were $1 / 29$ and $1 / 34 \mathrm{rad}$, respectively, exceeding the elastic story drift limit of 1/50 rad according to the Code for Seismic Design of Buildings Meanwhile, the peak strains of the ABRPSF and WBRPSF reached 2746.2 $\mu \varepsilon$ and $2198.8 \mu \varepsilon$, respectively, and the column foot flange of the ABRPSF was still in the elastic state. Both frames can still return to their original positions after an earthquake and indicated have good resilient capacities and excellent seismic behaviors.

Table 6

Strain development at typical regions for both steel frames under Wenchuan seismic records

\begin{tabular}{|c|c|c|c|c|c|c|c|c|}
\hline Steel frames & PGA & Flange of column foot & Panel zone & Reinforced plate & Flange of short beam & Flange of column base & Big L-plate & Small L-plate \\
\hline \multirow{8}{*}{ ABRPSF } & $0.07 \mathrm{~g}$ & 271.3 & 202.3 & 87.68 & 126.94 & 201.96 & 208.6 & 119.5 \\
\hline & $0.20 \mathrm{~g}$ & 487.0 & 548.0 & 918.0 & 377.0 & 448.0 & 387.0 & 313.0 \\
\hline & $0.40 \mathrm{~g}$ & 580.3 & 700.0 & 1031.3 & 451.0 & 666.0 & 707.0 & 671.0 \\
\hline & $0.51 \mathrm{~g}$ & 1090.1 & 809.2 & 1281.0 & 580.4 & 745.5 & 861.5 & 984.6 \\
\hline & $0.62 \mathrm{~g}$ & 1218.4 & 938.0 & 1529.5 & 685.0 & 823.8 & 958.4 & 1039.5 \\
\hline & $0.81 \mathrm{~g}$ & 1214.1 & 1168.8 & 1820.7 & 863.8 & 843.4 & 1021.5 & 1148.1 \\
\hline & $1.0 \mathrm{~g}$ & 1267.8 & 1364.6 & 1960.3 & 974.4 & 1035.3 & 1140.9 & 1119.1 \\
\hline & $1.2 \mathrm{~g}$ & 1746.7 & - & 2349.7 & 1079.9 & 1615.6 & 1392.2 & 1049.3 \\
\hline \multirow{8}{*}{ WBRPSF } & $0.07 \mathrm{~g}$ & 236.5 & 98.6 & 27.2 & 65.1 & 182.2 & - & - \\
\hline & $0.20 \mathrm{~g}$ & 700.1 & 307.5 & 144.0 & 278.2 & 569.9 & - & - \\
\hline & $0.40 \mathrm{~g}$ & 1044.1 & 385.8 & 487.8 & 666.5 & 932.2 & - & - \\
\hline & $0.51 \mathrm{~g}$ & 1136.2 & 472.4 & 764.4 & 732.0 & 1031.1 & - & - \\
\hline & $0.62 \mathrm{~g}$ & 1522.9 & 536.1 & 1148.3 & 882.5 & 1229.3 & - & - \\
\hline & $0.81 \mathrm{~g}$ & 1854.6 & 605.2 & 1320.7 & 995.01 & 1458.6 & - & - \\
\hline & $1.0 \mathrm{~g}$ & 1944.8 & 640.4 & 1643.4 & 1053.6 & 1624.9 & - & - \\
\hline & $1.2 \mathrm{~g}$ & 2198.8 & 745.5 & 1809.4 & 1235.5 & 1904.8 & - & - \\
\hline
\end{tabular}

Here, "_" refers to blank data or data with error.

\subsection{PT force}

Variations of the PT force of steel strand S1 for the ABRPSF and WBRPSF under different levels of EL-Centro seismic records are shown in Figs. 27(a)(d), where the ordinate represents the ratio of the actual PT force to the ultimate PT force. The initial PT force $\mathrm{T}_{0}$ of each steel strand for both steel frames were selected as $0.25 \mathrm{Tu}(0.25 \times 582=145.5 \mathrm{kN}$, where Tu is the ultimate PT force measuring $582 \mathrm{kN}$ ), which can provide adequate self-centering capacity and simultaneously avoid the potential issue of steel strand yielding.

As shown in Fig. 27, the PT force fluctuated around the initial PT force $(0.25 \mathrm{Tu})$ for both steel frames under a PGA of $0.07 \mathrm{~g}$, thereby causing no gap opening. When PGA $=0.20 \mathrm{~g}$, a slight gap opening occurred; consequently, several marked protruding points appeared on the time history curves of the PT force variation. The maximum PT forces of the ABRPSF and WBRPSF reached $0.252 \mathrm{Tu}$ and $0.254 \mathrm{Tu}$, respectively. With the increase in the gap openings, the length of the prestressed strand increased, causing the PT force to increase as well. When the PGA reached 0.40 and $0.51 \mathrm{~g}$, the PT force of both steel frames increased significantly, in which the maximum PT forces of the ABRPSF and WBRPSF when PGA $=0.40 \mathrm{~g}$ were $0.258 \mathrm{Tu}$ and $0.261 \mathrm{Tu}$, respectively, and when PGA $=0.51 \mathrm{~g}$, they were $0.261 \mathrm{Tu}$ and $0.263 \mathrm{Tu}$, respectively. It can be concluded that under various EL-Centro seismic levels, the PT force of the ABRPSF was smaller than that of the WBRPSF, and a slight PT force decrease occurred in both steel frames when the test was terminated, as shown in Table 7. 


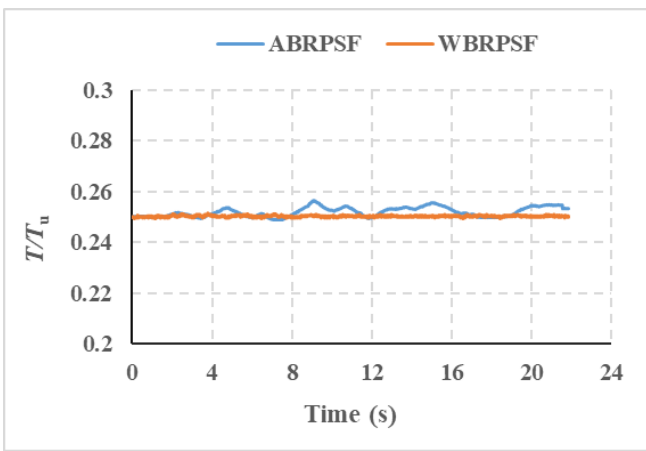

(a) $\mathrm{PGA}=0.07 \mathrm{~g}$

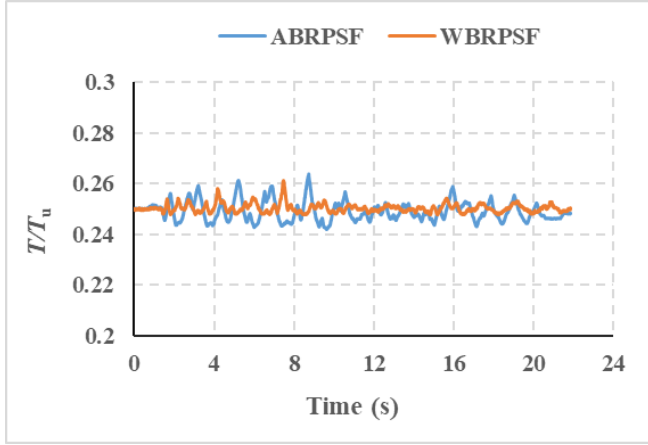

(c) $\mathrm{PGA}=0.40 \mathrm{~g}$

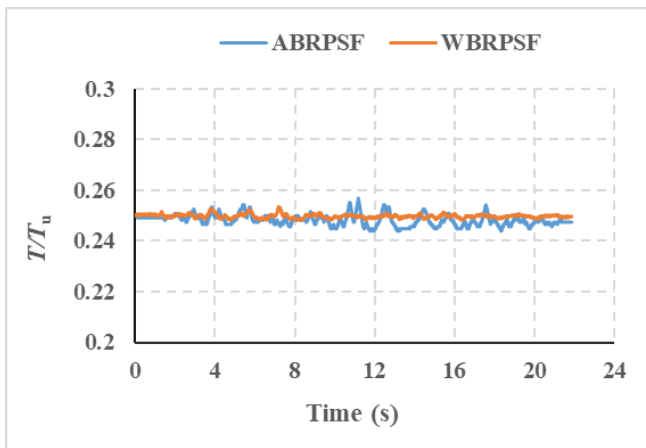

(b) $\mathrm{PGA}=0.20 \mathrm{~g}$

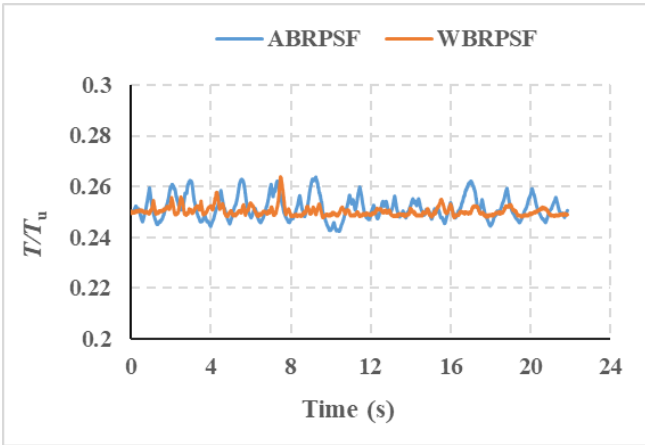

(d) $\mathrm{PGA}=0.51 \mathrm{~g}$

Fig. 27 PT force variations of both steel frames under different EL-Centro seismic levels

The variations in the PT force of the ABRPSF and WBRPSF under the Wenchuan seismic records are shown in Figs. 28(a)-(h). Similar to that under the EL-Centro seismic level, the variation in the PT force still fluctuated around the initial PT force when PGA $=0.20 \mathrm{~g}$. With the gap opening, the variation in the PT force increased significantly. When PGA $=0.40 \mathrm{~g}$, the maximum PT forces of the ABRPSF and WBRPSF were 0.269Tu and 0.281Tu, respectively, and under $0.51 \mathrm{~g}$, they were $0.270 \mathrm{Tu}$ and $0.278 \mathrm{Tu}$, respectively. Meanwhile, the PT forces of the ABRPSF and WBRPSF decreased by $6.46 \%$ and $1.51 \%$, respectively. When PGA $=0.62 \mathrm{~g}$, the maximum PT forces of the ABRPSF and WBRPSF were 0.301Tu and 0.323Tu, respectively; when the PGA reached $0.81 \mathrm{~g}$, the maximum PT forces increased to $0.305 \mathrm{Tu}$ and $0.336 \mathrm{Tu}$, respectively. With the increase in seismic levels, the maximum PT force continued to increase.

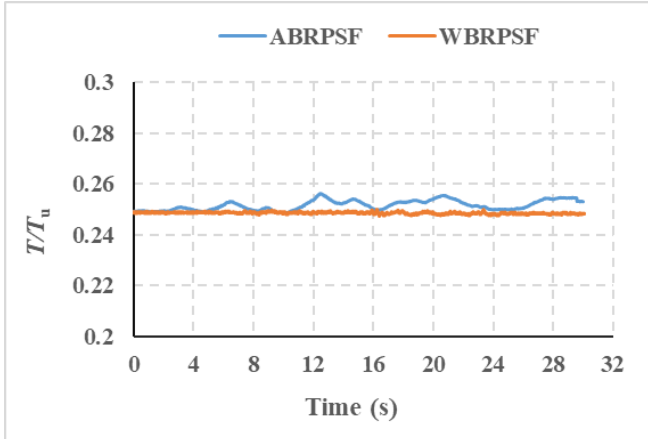

(a) $\mathrm{PGA}=0.07 \mathrm{~g}$

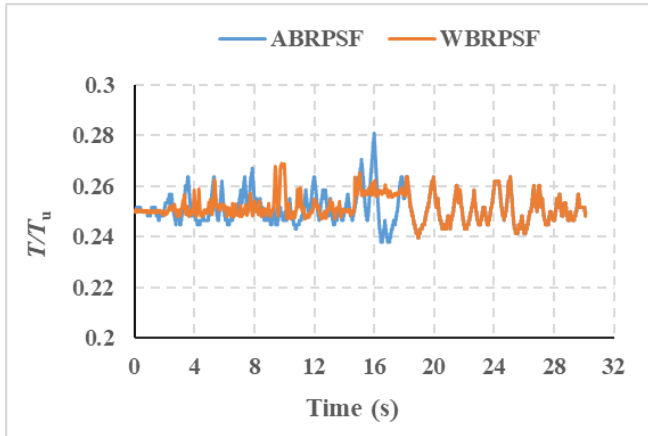

(c) $\mathrm{PGA}=0.40 \mathrm{~g}$
When the PGA increased to $1.0 \mathrm{~g}$, the maximum PT forces of the ABRPSF and WBRPSF reached 0.296Tu and 0.359Tu, respectively; when PGA was $1.2 \mathrm{~g}$, the maximum PT forces were $0.344 \mathrm{Tu}$ and $0.364 \mathrm{Tu}$, respectively. The PT force decrease of the ABRPSF and WBRPSF under the Wenchuan seismic records from 0.07 to $1.2 \mathrm{~g}$ was small, as shown in Table 7 . We observed that the maximum PT force for both steel frames showed similar variation trends, although the maximum PT force of the ABRPSF was relatively smaller than that of the WBRPSF because the L-plates underwent an elastic deformation and bolt slippage occurred on the beam-to-column connection of the ABRPSF; additionally, the slight decrease indicated that the strands, anchorage device performance, and prestressed method were reliable.

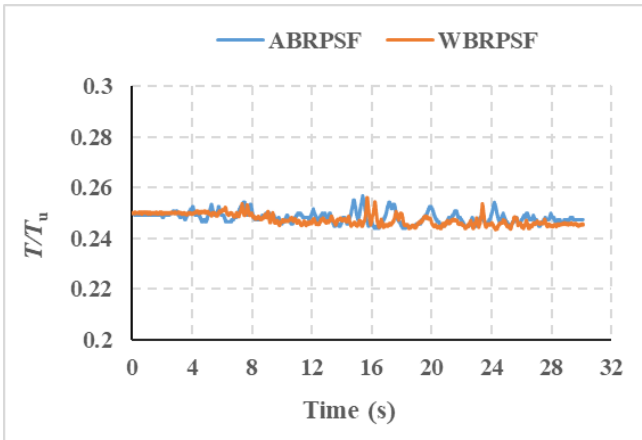

(b) $\mathrm{PGA}=0.20 \mathrm{~g}$

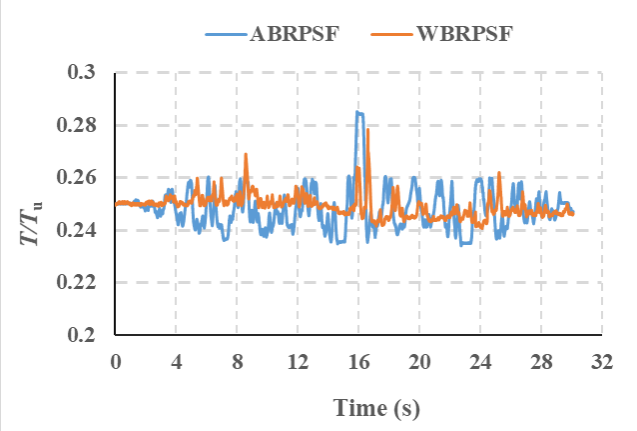

(d) $\mathrm{PGA}=0.51 \mathrm{~g}$ 


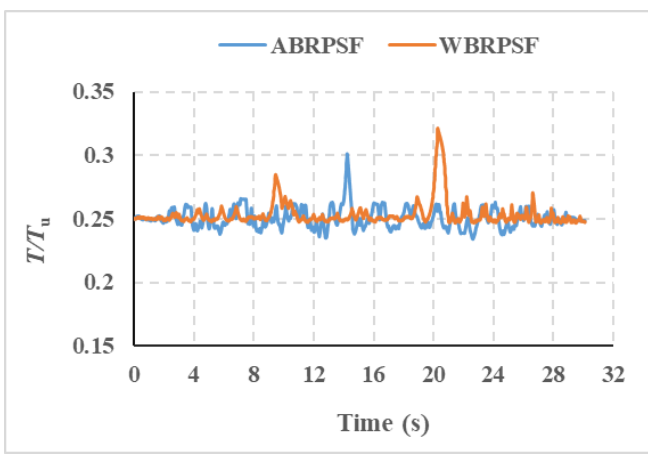

(e) $\mathrm{PGA}=0.62 \mathrm{~g}$

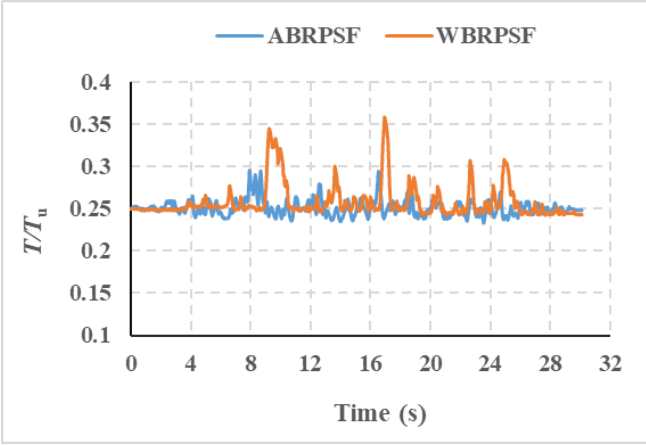

(g) $P G A=1.0 \mathrm{~g}$

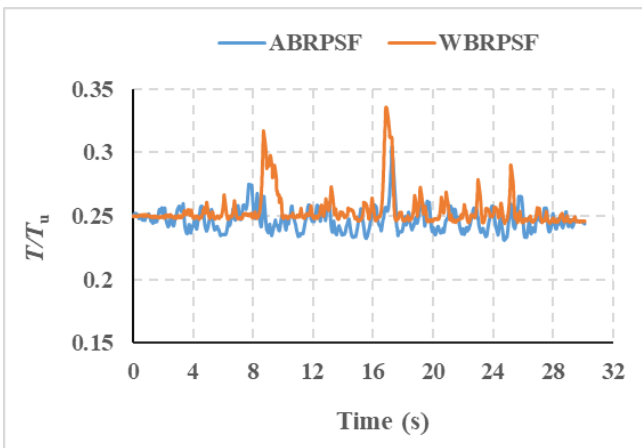

(f) $\mathrm{PGA}=0.81 \mathrm{~g}$

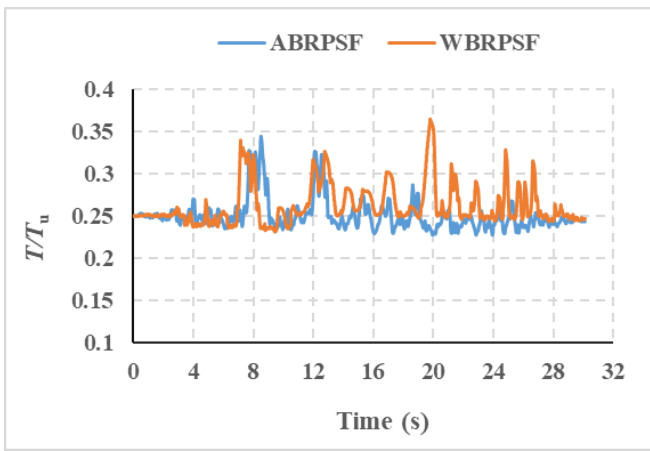

(h) $\mathrm{PGA}=1.2 \mathrm{~g}$

Fig. 28 PT force variations of both steel frames under different Wenchuan seismic levels

Table 7

PT force decrease under various seismic levels

\begin{tabular}{|c|c|c|c|c|c|c|c|}
\hline \multicolumn{2}{|c|}{ Seismic event } & \multicolumn{2}{|c|}{ initial PT force } & \multicolumn{2}{|c|}{ PT force decrease } & \multicolumn{2}{|c|}{ Ratio of PT force decrease } \\
\hline Ground motion & PGA & $T_{0} / \mathrm{kN}$ & $T_{0} / \mathrm{T}_{\mathrm{u}}$ & $\operatorname{ABRPSF}\left(T_{\mathrm{d}} / \mathrm{kN}\right)$ & WBRPSF $\left(T_{\mathrm{d}} / \mathrm{kN}\right)$ & ABRPSF & WBRPSF \\
\hline \multirow{4}{*}{ EL-Centro } & $0.07 \mathrm{~g}$ & 145.5 & 0.25 & 0.000 & 0.873 & $0.000 \%$ & $0.600 \%$ \\
\hline & $0.20 \mathrm{~g}$ & 145.5 & 0.25 & 0.287 & 2.172 & $0.197 \%$ & $1.493 \%$ \\
\hline & $0.40 \mathrm{~g}$ & 145.5 & 0.25 & 5.138 & 0.602 & $3.531 \%$ & $0.414 \%$ \\
\hline & $0.51 \mathrm{~g}$ & 145.5 & 0.25 & 0.562 & 0.863 & $0.386 \%$ & $0.593 \%$ \\
\hline \multirow{8}{*}{ Wenchuan } & $0.07 \mathrm{~g}$ & 145.5 & 0.25 & 0.000 & 1.050 & $0.000 \%$ & $0.722 \%$ \\
\hline & $0.20 \mathrm{~g}$ & 145.5 & 0.25 & 1.500 & 2.740 & $1.031 \%$ & $1.883 \%$ \\
\hline & $0.40 \mathrm{~g}$ & 145.5 & 0.25 & 1.000 & 1.000 & $0.687 \%$ & $0.687 \%$ \\
\hline & $0.51 \mathrm{~g}$ & 145.5 & 0.25 & 9.400 & 2.200 & $6.460 \%$ & $1.512 \%$ \\
\hline & $0.62 \mathrm{~g}$ & 145.5 & 0.25 & 0.800 & 1.240 & $0.550 \%$ & $0.852 \%$ \\
\hline & $0.81 \mathrm{~g}$ & 145.5 & 0.25 & 3.500 & 2.716 & 2.406 & 1.867 \\
\hline & $1.00 \mathrm{~g}$ & 145.5 & 0.25 & 1.000 & 4.250 & 0.687 & 2.921 \\
\hline & $1.20 \mathrm{~g}$ & 145.5 & 0.25 & 3.900 & 1.780 & 2.680 & 1.223 \\
\hline
\end{tabular}

\section{Summary and Conclusions}

An innovative ABRPSF was proposed and experimentally investigated by comparing it with a WBRPSF. Based on the comparison of pseudo-dynamic test results under various seismic levels, i.e., $\mathrm{PGA}=0.07,0.20,0.40,0.51,0.62$, $0.81,1.0$, and $1.2 \mathrm{~g}$ for both structural systems, the following conclusions were obtained:

(1) When PGA $=0.07 \mathrm{~g}$, the maximum story drifts of the ABRPSF and WBRPSF were $1 / 518$ and $1 / 529 \mathrm{rad}$, respectively, under the Wenchuan seismic records; those values did not exceed the elastic story drift limit $(1 / 250 \mathrm{rad})$ defined in the Code for Seismic Design of Buildings [28]. Furthermore, the maximum story drift of the ABRPSF was greater than that of the WBRPSF, indicating that the rigidity of the ABRPSF was slightly smaller than that of the WBRPSF. No gap opening or damage occurred in both steel frames under frequent earthquakes. The hysteretic curves of both steel frames presented a linear shape and both steel frames remained in the elastic state. The maximum PT forces of the steel strands of both steel frames were close to the initial value without any obvious decrease after a test was performed. The performances of both steel frames satisfied the design goal of "no gap opening and no damage occurs during frequent earthquakes."

(2) When the seismic level reached that of an 8-degree fortification earthquake with a PGA of $0.2 \mathrm{~g}$, the maximum story drifts of both steel frames under the Wenchuan seismic records were nearly identical, i.e., 1/173 and 1/171 rad for the ABRPSF and WBRPSF, respectively. The gap opening of the WBRPSF was slightly larger that of the ABRPSF, and the values for both remained at relatively low. Additionally, almost no residual gap opening was observed when loading completed, indicating that both steel frames possessed favorable recentering capacities. Both steel frames began to dissipate energy at this time, as observed from slight loops that formed in the hysteretic curves. Both steel frames remained in the elastic state during loading. The maximum PT force of the ABRPSF steel strands was less than that of the WBRPSF, and the PT forces of both steel frames almost did not decrease after the test. The performances of both steel frames satisfied the design goal of "gap openings are formed to dissipate energy and no damage occurs to the main structure under fortification earthquake action."

(3) When the PGA varied from 0.4 to $0.62 \mathrm{~g}$, the test results of the ABRPSF and WBRPSF presented similar trends. When PGA $=0.62 \mathrm{~g}$, the maximum story drift of the ABRPSF (1/56 rad) was greater than that of the WBRPSF $(1 / 65 \mathrm{rad})$, 
and both values did not exceed the elastoplastic story drift limit (1/50 rad) [28]. The gap-opening response of the ABRPSF was smaller than that of the WBRPSF owing to the bolt slippage and the elastic deformation of the L-plate for the connection of the ABRPSF. Furthermore, no residual gap openings were observed for both steel frames; both frames were able to return to their original positions upon rare or even extremely rare earthquakes. Additionally, the ABRPSF had a more satisfactory energy dissipating capacity than the WBRPSF owing to the dual energy dissipating mechanisms of bolt slippage on the beamto-column connection and the web friction device of the ABRPSF. Both steel frames remained in the elastic state under a 9-degree rare earthquake. The maximum PT force of the ABRPSF was still less than that of the WBRPSF, and the values of both did not exceed the yield strength of steel strands. After the test, the PT forces of both steel frames were still similar to the initial value, and both structures still possessed adequate re-centering and bearing capacities to endure intensive aftershocks upon rare earthquakes. The performance of both steel frames satisfied the design goal of "only small structural damage occurs and the structure can still operate normally during rare or extremely rare earthquakes."

(4) When the PGA increased to $0.81,1.0$, and $1.2 \mathrm{~g}$, the results of the ABRPSF and WBRPSF were similar. For example, when PGA $=1.2 \mathrm{~g}$, the maximum story drifts for the ABRPSF and WBRPSF were $1 / 29$ and 1/34 rad, respectively, and the gap openings of both steel frames developed further and exhibited the same trend as that of PGA $=0.62 \mathrm{~g}$. The residual gap openings of both steel frames were approximately zero, indicating that both steel frames can

\section{References}

[1] Ricles, J.M., Sause, R., Garlock, M.M. and Zhao. C., "Post-tensioned seis-mic-resistant connections for steel frames", Journal of Structural Engineering, 127(2), 113-121, 2001.

[2] Ricles, J.M., Sause, R., Peng, S. and Lu, L., "Experimental evaluation of earthquake resistant post-tensioned steel connections", Journal of Structural Engineering, 128(7), 850-859, 2002.

[3] Christopoulos, C., Filiatrault, A., Uang, C.M. and Folz, B., "Post-tensioned Energy Dissipating Connections for Moment-resisting Steel Frames", Journal of Structural Engineering, 128(9), 1111-1120, 2002.

[4] Tsai, K. C., Chou, C. C., Lin, C. L., Chen, P. C. and Jhang, S. J., "Seismic Self-centering Steel Beam-to- column Moment Connections using Bolted Friction Devices, "Earthquake Engineering and Structural Dynamics, 37, 627-645, 2008.

[5] Iyama, J., Seo, C.Y., Ricles, J.M. and Sause, R., "Self-centering MRFs with Bottom Flange Friction Devices under Earthquake Loading", Journal of Constructional Steel Research, 65, 314-325, 2009.

[6] Wolski, M., Ricles, J.M. and Sause, R., "Experimental Study of a Self-centering Beamcolumn Connection with Bottom Flange Friction Device", Journal of Structural Engineering, 135(5), 479-488, 2009

[7] Khoo, H.H., Clifton, C., Butterworth, J., MacRae, G., Gledhill, S. and Sidwell, G., "Development of the self-centering Sliding Hinge Joint with friction ring springs", Journal of Constructional Steel Research, 78, 201-211, 2012.

[8] Maria M. Garlock, James M. Ricles, Richard Sause. Experimental Studies of Full-Scale Posttensioned Steel Connections, 131(3), 438-448, 2005.

[9] Ying-Cheng Lin, Richard Sause, James Ricles. Seismic Performance of a Large-Scale Steel Self-Centering Moment-Resisting Frame: MCE Hybrid Simulations and Quasi-Static Pushover Tests, 139(7), 1227-1236, 2013.

[10] Ying-Cheng Lin, Richard Sause, James M. Ricles. Seismic Performance of Steel SelfCentering, Moment-Resisting Frame: Hybrid Simulations under Design Basis Earthquake, 139(11), 1823-1832, 2013

[11] Apostolakis, G., Dargush, G.F. and Filiatrault, A., "Computational Framework for Automated Seismic Design of Steel Frames with Self-Centering Connections", Journal of Computing in Civil Engineering, 28(2), 170-181, 2014

[12] George Vasdravellis, Theodore L. Karavasilis, Brian Uy. Finite element models and cyclic behavior of self-centering steel post-tensioned connections with web hourglass pins, Engineering Structures, 52, 2013.

[13] Xu, X, Zhang, Y.F., Luo, Y.Z, "Self-centering modularized link beams with post-tensioned shape memory alloy rods", Engineering Structures 112, 47-59, 2016.

[14] Sultana, P., Youssef, M.A. "Seismic performance of steel moment resisting frames utilizing superelastic shape memory alloys", Journal of Constructional Steel Research, 125, 239-251, 2016

[15] Farmani, M.A. and Ghassemieh, M. "Steel beam-to-column connections equipped with SMA tendons and energy dissipating devices including shear tabs or web hourglass pins", Journal of Constructional Steel Research, 135, 30-48,2017.

[16] Yam, F.C., M., C.H., Lam, A.C.C. Xie, L.K., "Cyclic performance of extended end-plate connections equipped with shape memory alloy bolts", Journal of Constructional Steel Research, 94, 122-136, 2014

[17] Wei Wang, Cheng Fang, Jia Liu. Self-Centering Beam-to-Column Connections with Combined Superelastic SMA Bolts and Steel Angles, Journal of Structural Engineering, 2016.

[18] Miller, D.J., Fahnestock, L.A., Eatherton, M.R., "Development and experimental validation of a nickel-titanium shape memory alloy self-centering buckling-restrained brace", Engineering Structures, 40, 288-298, 2012.

[19] Qiu, C.X., Zhu, S.Y., "Performance-based seismic design of self-centering steel frames with SMA-based braces", Engineering Structures, 130, 67-82, 2017

[20] Dezfuli, M.A., Dolatshahi, K.M., Mofid, M., Eshkevari, S.S., "Coreless self-centering braces as retrofitting devices in steel structures", Journal of Constructional Steel Research, 133, 485-498, 2017.

[21] Zhang, Y.X., Li, Z.X., Liu, A.R., Li, R. and Liu, X.C., "Research on the behavior of selfcentering replaceable mild steel energy-dissipating braces", ENGINEERING MECHANICS, 34(8), 180-193. 2017

[22] Zhang, Y.X., Li, Z.X., Zhao, W.Z., Li, R., and Li, J.R., "A Performance Study of Beam Column Connections of Self-centering Steel Frame with U-shaped Steel Dampers", Advanced Steel Construction, 12(4), 446-465, 2016

[23] Zhang, A.L., Zhang, Y.X., Li, R. and Wang, Z. Y., "Cyclic Behavior of a Prefabricated Self- still return to their original positions upon extremely rare earthquakes. The new ABRPSF demonstrated more satisfactory energy dissipation performances than the WBRPSF, as observed from the hysteretic curves. As the PGA increased to $0.81 \mathrm{~g}$, the column foot flange of the WBRPSF entered the plastic state; however, the column foot flange of the ABRPSF still remained in the elastic state until PGA $=1.2 \mathrm{~g}$, indicating that the ABRPSF performed better in avoiding plastic damage under rare earthquakes. Under various seismic levels, the PT forces of both steel frames almost did not decrease, indicating that the strands, anchorage device performance, and prestressed method were reliable. Both steel frames demonstrated favorable resilient capacities and satisfying seismic behaviors, and the new ABRPSF can be regarded as a reliable alternative to the WBRPSF

\section{Acknowledgements}

This study is supported by the National Natural Science Foundation of China under Grant No. 51778036, Beijing Municipal Natural Science Foundation under Grant No. 19JH0021, Program for Changjiang Scholars and Innovative Research Team in University under Grant No. IRT_17R06, the Fundamental Research Funds for Beijing Universities under Grant Nos. X19024, X19034, and X19035, Beijing Advanced Innovation Center for Future Urban Design, Beijing University of Civil Engineering and Architecture (Research on Application Technology of High-efficiency Assembly Steel Structure System in Medical Building UDC2019033124), and Science and Technology Program of the Ministry of Housing and Urban-Rural Development (2017-K9-033)

centering Beam-column Connection with a Bolted Web Friction Device", Engineering Structures, 111, 185-198, 2016

[24] Zhang, Y.X., Wang, Z.Y., Zhao, W., Zhao, W.Z., and Chen, Y.Y., " A pseudo-dynamic test study on a self-centering prefabricated steel frame with a column base connected by semirigid joints", Advanced Steel Construction, 12(3), 296-315, 2016.

[25] Zhang, Y.X, Liu, A.R., Zhang, A.L. and Liu, X.C., "Seismic performance analysis of a resilient prestressed steel frame with intermediate column containing friction dampers", Advanced Steel Construction, 13(3), 241-257, 2017.

[26] Zhang, Y.-X., Li, Q.-G., Huang, W.-Z., Jiang, K., Sun, Y.. Behavior of prefabricated beamcolumn connection with short strands in self-centering steel frame. Advanced Steel Construction. 15(2), 203-214, 2019.

[27] GB50019-2017, Standards for design of steel buildings. Beijing: China Architecture \& Building Press; 2016. [in Chinese].

[28] GB50011-2016, Code for seismic design of buildings. Beijing: China Architecture \& Building Press; 2016. [in Chinese]. 